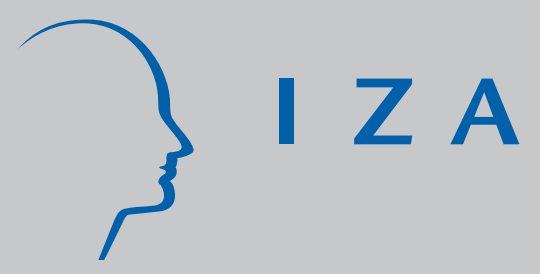

IZADP No. 3522

Outsourcing and Labor Taxation in Dual Labor Markets

Erkki Koskela

Panu Poutvaara

May 2008 


\title{
Outsourcing and Labor Taxation in Dual Labor Markets
}

\author{
Erkki Koskela \\ University of Helsinki \\ and IZA \\ Panu Poutvaara \\ University of Helsinki \\ and IZA
}
Discussion Paper No. 3522
May 2008

\author{
IZA \\ P.O. Box 7240 \\ 53072 Bonn \\ Germany \\ Phone: +49-228-3894-0 \\ Fax: +49-228-3894-180 \\ E-mail: iza@iza.org
}

\begin{abstract}
Any opinions expressed here are those of the author(s) and not those of IZA. Research published in this series may include views on policy, but the institute itself takes no institutional policy positions.

The Institute for the Study of Labor (IZA) in Bonn is a local and virtual international research center and a place of communication between science, politics and business. IZA is an independent nonprofit organization supported by Deutsche Post World Net. The center is associated with the University of Bonn and offers a stimulating research environment through its international network, workshops and conferences, data service, project support, research visits and doctoral program. IZA engages in (i) original and internationally competitive research in all fields of labor economics, (ii) development of policy concepts, and (iii) dissemination of research results and concepts to the interested public.
\end{abstract}

IZA Discussion Papers often represent preliminary work and are circulated to encourage discussion. Citation of such a paper should account for its provisional character. A revised version may be available directly from the author. 


\begin{abstract}

\section{Outsourcing and Labor Taxation in Dual Labor Markets}

We evaluate the effects of international outsourcing and labor taxation on wage formation and equilibrium unemployment in dual labor markets. Outsourcing promotes wage dispersion between the high-skilled and low-skilled workers. Higher domestic low-skilled wage tax, higher payroll tax and lower wage tax exemption increase optimal outsourcing. Outsourcing will reduce equilibrium unemployment of low-skilled workers both in the presence and absence of labor taxation. In the presence of outsourcing, wage tax, tax exemption and payroll tax have an ambiguous effect on equilibrium unemployment. Increasing the degree of tax progression decreases the wage rate and increases the demand of low-skilled workers.
\end{abstract}

JEL Classification: E24, J21, J31, J51, J82, H22

Keywords: outsourcing, dual labor markets, labor taxation, equilibrium unemployment

Corresponding author:

Erkki Koskela

Department of Economics

University of Helsinki

P.O. Box 17 (Arkadiankatu 7)

00014 Helsinki

Finland

E-mail: erkki.koskela@helsinki.fi

\footnotetext{
"We thank seminar participants in CESifo area conference on "Employment and social protection", May 2008, for comments. The authors acknowledge financial support from the Research Unit of Economic Structures and Growth (RUESG), financed by the Academy of Finland, the University of Helsinki, the Yrjö Jahnsson Foundation, the Bank of Finland and the Nokia Group. Koskela also thanks the Academy of Finland (grant No. 1117698) for further financial support. Poutvaara gratefully acknowledges the hospitality by the Center for Economic Studies in Munich during the writing process.
} 


\section{Introduction}

High wage differences across countries constitute an important explanation for the currently significant business practice of international outsourcing. These wage differentials could lead to outsourcing (see e.g. Sinn (2007) for details, and Stefanova (2006) concerning the East-West dichotomy of outsourcing). Glass and Saggi (2001) have studied the causes of outsourcing and its effects and they found that higher international outsourcing lowers the relative wage of domestic workers compared with foreign workers, while it increases the profits and thereby creates greater incentives for innovation. We are not aware of any existing study, which would have studied theoretically the employment consequences of international outsourcing with unionized labor markets. ${ }^{1}$ We analyze the effects of international outsourcing to low-wage countries and the effects of labor taxation on equilibrium unemployment of low-skilled workers and labor demand. Our analysis applies to high-wage countries characterized by heterogenous in-house workers in the dual labor markets when there is both unionized and competitive determination of wages.

We show that both the own wage elasticity, the cross wage elasticity and the outsourcing elasticity for the low-skilled labor demand depend positively on the amount of outsourcing, and these wage elasticities also depend positively on the payroll tax, whereas the own wage elasticity, the cross wage elasticity and the outsourcing elasticity for the high-skilled labor demand are independent of the amount of outsourcing. In the presence of outsourcing the high-skilled wage formation depends negatively on the low-skilled wage and the payroll tax, whereas the high-skilled wage is independent of the high-skilled wage tax parameters under Cobb-Douglas utility function. In terms of low-skilled wage determination a higher share of outsourced production and a higher productivity of outsourced production will decrease the wage for the low-skilled labor

\footnotetext{
${ }^{1}$ There are some papers that analyze the effects of outsourcing when labor is heterogeneous, like Davidson et al. (2007) and Davidson et al. (forthcoming). However, these papers analyze labor market frictions that arise with search, while we focus on the role of labor unions. Importantly, the effects of taxation on unemployment may differ even qualitatively between models with labor unions and with search-related unemployment. If wages are determined competitively or as in the shirking efficiency wage model, the structure of taxation is irrelevant to the impact of the tax cut (see e.g. Pissarides (1998)). But if wages are determined by a bargain also in search models, changes in the structure of taxation have large impacts on employment, which has been shown in Pissarides (1998).
} 
and increase the wage for the high-skilled labor, thereby inducing higher wage dispersion. A higher low-skilled wage tax will increase the wage for the low-skilled labor, decrease the wage of high-skilled labor and a higher low-skilled wage tax exemption will decrease the wage for the low-skilled labor and increase the wage for the high-skilled labor, while a higher payroll tax for the firms will decrease the wage for the low-skilled labor and also decrease the wage for the high-skilled labor.

In terms of optimal committed outsourcing policy parameters affect as follows: a higher domestic low-skilled wage tax and a higher unemployment benefit increase optimal outsourcing, while a higher tax exemption, ceteris paribus, decreases optimal outsourcing, and a higher payroll tax for the firms will have an ambiguous effect on optimal outsourcing.

Finally, in terms of the effects of outsourcing and some policy variables on equilibrium unemployment of low-skilled workers we have the following result if benefit-replacement ratio is constant for the unemployed: A higher amount of outsourced production will reduce equilibrium unemployment of low-skilled workers both in the absence and presence of progressive wage taxation and proportional payroll taxation.

In the presence of outsourcing the higher wage tax, the higher tax exemption and the higher payroll tax will have an ambiguous effect on equilibrium unemployment, when the benefit-replacement ratio is fixed and less than one. In the absence of outsourcing the higher wage tax will have a positive and the higher tax exemption will have a negative effect on equilibrium unemployment, while the higher payroll tax will have no effect. In the presence of outsourcing increasing the degree of tax progression by keeping the relative tax burden per worker constant by raising the wage tax and the tax exemption will decrease the wage rate and increase the labor demand of low-skilled workers. This result is qualitatively similar in the absence of outsourcing.

We proceed as follows. Section II presents the time sequence of the decisions regarding some policy issues associated with labor taxes, outsourcing, wage setting for low-skilled workers and labor demand for high-skilled and low-skilled workers and the wage setting for high-skilled workers. We study the segmented labor demand for heterogenous labor force and wage formation of high-skilled workers due to market 
equilibrium under labor taxation in section III. The wage formation by the monopoly labor union for low-skilled workers under linearly progressive wage tax, levied on workers, and proportional payroll tax, levied on firms, is analyzed in section IV. Section V explores how the optimal committed production mode from the firms' point of view in the presence of partly imperfectly competitive and segmented labor market depends on various important policy variables. In section VI we explore some policy issues concerning equilibrium unemployment and labor demand of low-skilled domestic workers. Finally, we summarize conclusions in section VII.

\section{The Basic Framework}

We analyze a model with heterogeneous workers and international outsourcing. The production combines labor services by high-skilled workers and low-skilled workers. Low-skilled labor services can be provided either by the firm's own workers, or obtained from abroad through international outsourcing.

Establishing international outsourcing is time-consuming, and reversing such decisions is often costly. Therefore, we assume that the firms have to commit to outsourcing before they hire domestic labor. Whether the firms or the government moves first, is an open question, a priori. We assume that the government decides on taxation and unemployment benefits before the firms decide on their international outsourcing. There are two motivations for this. First of all, major overhauls of tax systems are rather rare, and thus tax systems appear more stable than outsourcing decisions by individual firms. Second, the tax parameters to which we assume the government to commit could be viewed as an equilibrium outcome of a repeated game. Without commitment on the government's part, the tax parameters that the firms expect the government to choose ex ante would simply correspond to what is optimal for the government to choose ex post. The timing of event is depicted as Figure 1. The government sets its policy at stage 1 . At stage 2, the firms make investment in

outsourcing. At stage 3, conditional on policy choices by the government and the outsourcing decisions by the firms, the labor union determines the wage for the low- 
skilled workers. When deciding on its wage demand, the monopoly union of each industry takes into account how this affects the demand for labor by the firms. We assume that there are many industries, so that each labor union represents only a small fraction of the total labor force. At stage 4, firms decide on domestic employment. The high-skilled labor wage adjusts to equalize labor demand and labor supply.

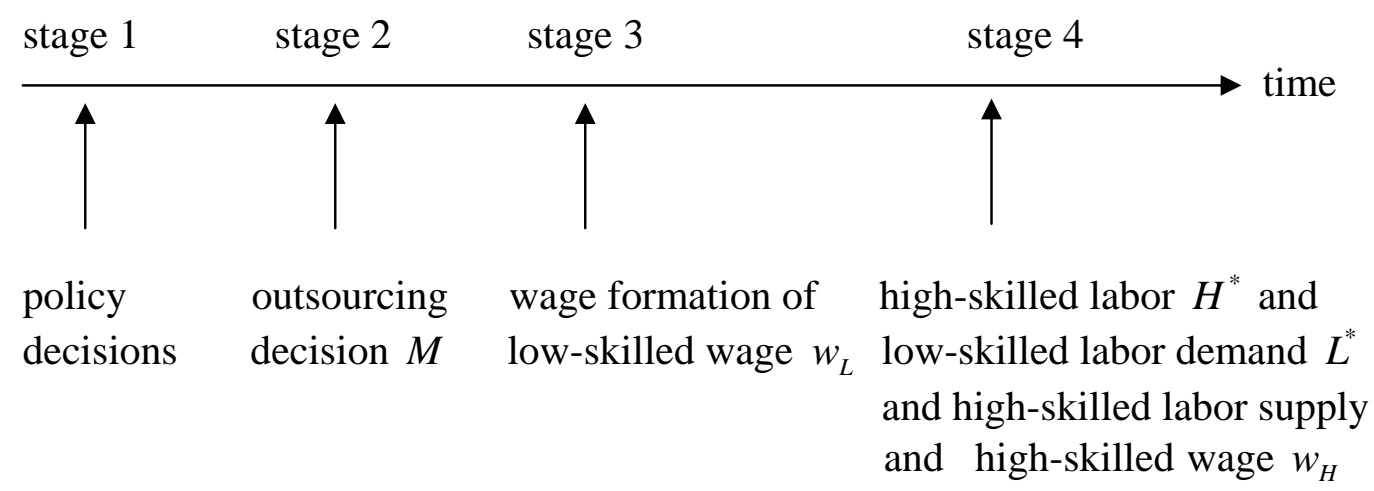

Figure 1: Time sequence of decisions

The decisions at each stage are analyzed by using backward induction. There are high-skilled and low-skilled workers and we assume that high-skilled wage formation is determined by the equality of the high-skilled labor demand and labor supply and the low-skilled wage rate is determined by the labor union subject to labor demand. ${ }^{2}$ This timing structure seems plausible as a starting point when the implementation of a production mode with outsourcing compared with domestic labor demand and wage formation requires irreversible investment concerning the establishment of a network of foreign supplies. Of course, the relative timing of wage formation and outsourcing would be different if the firms flexibly adjust their production mode, and decide whether to initiate foreign outsourcing after the domestic low-skilled wage is determined. $^{3}$

\footnotetext{
2 This has also been analyzed a little bit in Lingens and Waelde (2006), but they have abstracted from outsourcing issues.

3 Skaksen (2004) has analyzed this case using a Cobb-Douglas production function applied only to a homogenous domestic labor force. Also Braun and Scheffel (2007) have developed a simple two-stage game between a monopoly union and a firm by assuming that the labor union sets wages before the firms decide on the degree of outsourcing. They have argued that under such flexible outsourcing the cost of outsourcing has an ambiguous effect on the wage set by the labor union.
} 


\section{High-Skilled and Low-Skilled Labor Demand and the Wage Formation of High-Skilled Workers under Labor Taxation}

\section{III.1. High-Skilled and Low-Skilled Labor Demand}

At the last stage, the firm decides on the high-skilled labor demand $H$ and the low-skilled labor demand $L$ in order to maximize the profit function, taking the acquired amount of outsourcing, $M$, as given,

$$
\underbrace{\operatorname{Max}}_{(H, L)} \pi=F(H, L, M)-\tilde{w}_{H} H-\tilde{w}_{L} L-g(M)
$$

where each firm takes the gross wage for high-skilled labor, $\widetilde{w}_{H}=w_{H}(1+s)$, the gross wage for low-skilled labor, $\widetilde{w}_{L}=w_{L}(1+s)$, and the outsourced low-skilled labor input $M$ as given, where $s$ is the proportional payroll tax levied on the firm. Under outsourced production firms acquire the low-skilled labor input at the factor price $c$, which is lower than the wage of domestic low-skilled workers. In order to obtain $M$ units of outsourced low-skilled labor input firms have to make irreversible investment $g(M)=0.5 c M^{2}$ with $g^{\prime}(M)=c M>0$ and $g^{\prime \prime}(M)=c>0$ into the establishment of networks of suppliers in the relevant low-wage country.

We follow Koskela and Stenbacka (2007) by assuming a general and reasonable Cobb-Douglas-type production function with decreasing returns to scale according to $F(H, L, M)=\left[H^{a}(L+\gamma M)^{1-a}\right]^{\rho}$, where the parameters $\rho$ and $a$ are assumed to satisfy: $0<\rho<1$ and $0<a<1$. The parameter $\gamma>0$ captures the productivity of the outsourced low-skilled labor input relative to the domestic low-skilled labor input. The marginal products of high-skilled and low-skilled labor are $F_{H}=\rho Y^{\rho-1} a H^{a-1}(L+\gamma M)^{1-a} \quad$ and $\quad F_{L}=\rho Y^{\rho-1} H^{a}(1-a)(L+\gamma M)^{-a}$, respectively, where $Y=H^{a}(L+\gamma M)^{1-a}$. The outsourced low-skilled labor input affects the marginal products of the domestic high-skilled and low-skilled labor inputs as follows: 


$$
\begin{gathered}
F_{H M}=\rho^{2} Y^{\rho-1} a H^{a-1}(1-a) \gamma(L+\gamma M)^{-a}>0 \\
F_{L M}=-\rho Y^{\rho-1} H^{a}(1-a) \gamma(L+\gamma M)^{-a-1}[1-\rho(1-a)]<0 .
\end{gathered}
$$

Thus, for this production function the domestic high-skilled labor input and the outsourced low-skilled labor input are complements, whereas the low-skilled domestic labor input and the outsourced low-skilled labor input are substitutes in terms of the marginal product effects of outsourcing. Also one can calculate in the similar way that the domestic high-skilled and low-skilled labor are complements, i.e. $F_{H L}>0$. Given both the outsourcing decision and the wages the first-order conditions characterizing the domestic high-skilled and low-skilled labor demands are

$$
\begin{aligned}
& \pi_{H}=\rho\left[H^{a}(L+\gamma M)^{1-a}\right]^{\rho-1} a H^{a-1}(L+\gamma M)^{1-a}-\widetilde{w}_{H}=0 \\
& \pi_{L}=\rho\left[H^{a}(L+\lambda M)^{1-a}\right]^{\rho-1}(1-a) H^{a}(L+\gamma M)^{-a}-\widetilde{w}_{L}=0 .
\end{aligned}
$$

These first-order conditions imply the following relationship between the high-skilled labor $(H)$ and the low-skilled labor inclusive of outsourcing $(L+\gamma M)$

$$
H=\frac{w_{L}}{w_{H}} \frac{a}{1-a}(L+\gamma M)
$$

Substituting (4) into (3b) gives (see Appendix A) the low-skilled labor demand, which can be expressed as follows

$$
L^{*}=m w_{L}^{-\varepsilon_{L}^{L}} w_{H}^{-\varepsilon_{H}^{L}}(1+s)^{-\varepsilon}-\gamma M
$$

where $m=\left[\rho a^{a \rho}(1-a)^{1-a \rho}\right]^{\frac{1}{1-\rho}}>0,\left.\quad \varepsilon_{L}^{L}\right|_{M=0}=-\frac{L_{w_{L}} w_{L}}{L}=\frac{1-\rho a}{1-\rho}>1$ denotes the own wage elasticity of the low-skilled labor and $\left.\varepsilon_{H}^{L}\right|_{M=0}=-\frac{L_{w_{H}} w_{H}}{L}=\frac{\rho a}{1-\rho}>0$ denotes the cross wage elasticity of the low-skilled labor with respect to the high-skilled wage in 
the absence of outsourcing ${ }^{4}$. These elasticities are higher with weaker decreasing returns to scale. Higher own wage and cross wage will affect negatively the low-skilled labor demand. In the absence of outsourcing the payroll tax elasticity of the low-skilled labor is $\varepsilon=-\frac{L_{s}(1+s)}{L}=\frac{1}{1-\rho}>1$. According to (5), a more extensive outsourcing activity will decrease the low-skilled labor demand. This feature is consistent with empirical evidence. ${ }^{5}$

In the presence of outsourcing $M$ the wage elasticities of the low-skilled labor,

$$
\begin{gathered}
-\left.\frac{L_{w_{L}}^{*} w_{L}}{L^{*}}\right|_{M>0} \text { and }-\left.\frac{L_{w_{H}}^{*} w_{H}}{L^{*}}\right|_{M>0} \text {, can be written as follows } \\
\hat{\varepsilon}_{L}^{L}=\varepsilon_{L}^{L}\left(1+\gamma \frac{M}{L^{*}}\right)
\end{gathered}
$$

and

$$
\begin{aligned}
& \text { so that } \frac{\partial \hat{\varepsilon}_{L}^{L}}{\partial M}=\varepsilon_{L}^{L} \gamma\left[\frac{L^{*}-M L_{M}^{*}}{L^{* 2}}\right]=\varepsilon_{L}^{L} \frac{\gamma}{L^{*}}\left(1+\gamma \frac{M}{L^{*}}\right)=\frac{\gamma}{L^{*}} \hat{\varepsilon}_{L}^{L}>0 \quad \text { and } \\
& \frac{\partial \hat{\varepsilon}_{H}^{L}}{\partial M}=\varepsilon_{H}^{L} \gamma\left[\frac{L^{*}-M L_{M}^{*}}{L^{* 2}}\right]=\varepsilon_{H}^{L} \frac{\gamma}{L^{*}}\left(1+\gamma \frac{M}{L^{*}}\right)=\frac{\gamma}{L^{*}} \hat{\varepsilon}_{H}^{L}>0 \text {. These are in conformity with }
\end{aligned}
$$

empirical evidence according to which higher outsourcing increases the wage elasticity of low-skilled labor demand. ${ }^{6}$

\footnotetext{
${ }^{4}$ In the presence of perfect substitutability between two types of labour inputs, i.e. between $L$ and $M$, we would have $\gamma=1$, but it is important to mention that qualitative results are similar.

${ }^{5}$ For instance Diehl (1999) has presented empirical evidence from German manufacturing industries in support of this hypothesis. Moreover, Görg and Hanley (2005) have used plant-level data of the Irish electronic sector to empirically conclude that international outsourcing reduces plant-level labor demand.

${ }^{6}$ Senses (2006) has provided empirical evidence according to which a production mode with more outsourcing seems to increase the wage elasticity of labor demand. Also Slaughter (2001) and Hasan, Mitra and Ramaswamy (2007) have shown in terms of empirics that international trade has increased the wage elasticity of labor demand.
} 
Moreover, the elasticity of low-skilled labor with respect to outsourcing is positive, i.e. $\left.\varepsilon_{M}^{L}=-\frac{L_{M}^{*} M}{L^{*}}=\frac{\gamma M}{\left[m w_{L}^{-\varepsilon_{L}^{L}} W_{H}^{-\varepsilon_{H}^{L}}(1+s)^{-\varepsilon}-\gamma M\right]}\right]^{>0}$. Differentiating this with respect to $M$ gives

$$
\frac{\partial \varepsilon_{M}^{L}}{\partial M}=\frac{m w_{L}^{-\varepsilon_{L}^{L}} w_{H}^{-\varepsilon_{H}^{L}}(1+s)^{-\varepsilon} \gamma}{\left[m w_{L}^{-\varepsilon_{L}^{L}} w_{H}^{-\varepsilon_{H}^{L}}(1+s)^{-s}-\gamma M\right]^{2}}=\frac{\left(L^{*}+\lambda M\right) \gamma}{L^{* 2}}=\frac{\gamma}{L^{*}}\left(1+\gamma \frac{M}{L^{*}}\right)>0
$$

so that higher outsourcing will increase the outsourcing elasticity of the low-skilled labor. Differentiating (6a) with respect to the payroll tax gives

$$
\frac{\partial \hat{\varepsilon}_{L}^{L}}{\partial s}=\varepsilon_{L}^{L}\left[-\frac{\gamma M L_{s}^{*}}{L^{* 2}}\right]=\frac{\varepsilon_{L}^{L}}{(1+s)} \frac{\gamma M}{L^{*}} \varepsilon\left(1+\gamma \frac{M}{L^{*}}\right)=\frac{\varepsilon}{(1+s)} \frac{\gamma M}{L^{*}} \hat{\varepsilon}_{L}^{L}>0
$$

according to which the payroll tax in the presence of outsourcing will have a positive effect on the wage elasticity of the low-skilled labor demand. Comparative statics are qualitative similar in terms of $\hat{\varepsilon}_{H}^{L}$ and $\varepsilon_{M}^{L}$. Of course there is no wage elasticity effect of payroll tax in the absence of outsourcing, i.e. $\left.\frac{\partial \hat{\varepsilon}_{L}^{L}}{\partial s}\right|_{M=0}=0$. In the presence of outsourcing the payroll tax elasticity of the low-skilled labor, $-\left.\frac{L_{s}^{*}(1+s)}{L^{*}}\right|_{M>0}$, is

$$
\hat{\varepsilon}=\varepsilon\left(1+\gamma \frac{M}{L^{*}}\right)
$$

where $\varepsilon=\frac{1}{1-\rho}>1$ so that higher outsourcing raises this elasticity as well, i.e. $\frac{\partial \hat{\varepsilon}}{\partial M}=\varepsilon \frac{\gamma}{L^{*}}\left(1+\gamma \frac{M}{L^{*}}\right)=\frac{\gamma}{L^{*}} \hat{\varepsilon}>0$. Also to the payroll tax we have $\frac{\partial \hat{\varepsilon}}{\partial s}>0$.

Finally, substituting the RHS of equation (5) into the relationship between the high-skilled and low-skilled labor presented in equation (4) gives the following optimal demand for the high-skilled labor 


$$
H^{*}=\frac{m a}{1-a} w_{H}^{-\varepsilon_{H}^{H}} w_{L}^{-\varepsilon_{L}^{H}}(1+s)^{-\varepsilon},
$$

where $\varepsilon_{H}^{H}=-\frac{H_{w_{H}}^{*} w_{H}}{H^{*}}=\frac{1-\rho(1-a)}{1-\rho}>1, \varepsilon_{L}^{H}=-\frac{H_{w_{L}}^{*} w_{L}}{H^{*}}=\frac{\rho(1-a)}{1-\rho}>0$ and

$\varepsilon=-\frac{H_{s}^{*}(1+s)}{H^{*}}=\frac{1}{1-\rho}>1$. These elasticities are also higher with weaker decreasing

returns to scale, but unlike in the case with the low-skilled labor, both the own wage and cross wage labor demand elasticities, and the payroll tax elasticity for the highskilled labor are independent of outsourcing, while higher own wage, cross wage and payroll tax will affect negatively the high-skilled labor demand.

We can now summarize our findings regarding the properties of the domestic demand for labor in the presence of outsourcing as follows.

\section{Proposition 1 In the presence of outsourcing}

(a) the own wage elasticity, the cross wage elasticity and the outsourcing elasticity for the low-skilled labor demand depend positively on the amount of outsourcing, and they also depend positively on the payroll tax, whereas

(b) the own wage elasticity, the cross wage elasticity and the outsourcing elasticity for the high-skilled labor demand are independent of the amount of outsourcing and the payroll tax.

Proposition 1 reveals an asymmetry in how the demand for high-skilled and low-skilled labor react to the amount of outsourcing and the level of payroll taxes. An increase in outsourcing or payroll taxes would increase the own wage elasticity, the cross wage elasticity and the outsourcing elasticity for the low-skilled labor demand, while having no effect on the elasticities for the high-skilled labor demand. 


\section{III.2. Wage Formation for High-Skilled Workers under Labor Taxation}

\section{III.2.1 Optimal Labor Supply of High-Skilled Workers}

We assume that the market equilibrium for the high-skilled wage $w_{H}$ follows from the equality of the labor demand and the labor supply. First we derive labor supply and after that the wage formation from market equilibrium by taking the lowskilled wage $w_{L}$ as given.

We assume that the government can employ the proportional wage tax $t_{H}$ for high-skilled workers, which is levied on the wage rate $w_{H}$ minus tax exemption $e_{H}$. Thus the total tax base is $\left(w_{H}-e_{H}\right) H$, where $H$ is labor supply. In the presence of positive tax exemption the marginal wage tax exceeds the average wage tax rate $t_{H}\left(1-e_{H} / w_{H}\right)$ so that the system is linearly progressive. ${ }^{7}$ The net-of-tax wage that the high-skilled worker receives is $\hat{w}_{H}=\left(1-t_{H}\right) w_{H}+t_{H} e_{H}$.

We assume that the labor supply of the high-skilled worker is determined by utility maximization. In the case of the Cobb-Douglas utility function the elasticity of substitution is equal to one in terms of consumption $C$ and leisure $1-H$ in the utility function, i.e. $U(C, H)=C^{\mu}(1-H)^{1-\mu}, 0<\mu<1$. Maximizing $U(C, H)=C^{\mu}(1-H)^{1-\mu}$ s.t. $\hat{w}_{H} H=C$ with respect to labor supply $H$ gives $U_{H}=\mu\left(\hat{w}_{H} H\right)^{\mu-1}(1-H)^{1-\mu}-(1-\mu)\left(\hat{w}_{H} H\right)^{\mu}(1-H)^{-\mu}=0$ so that

$$
H^{s}=\mu
$$

Therefore under this assumption the net-of-tax wage $\hat{w}_{H}=\left(1-t_{H}\right) w_{H}+t_{H} e_{H}$ will have no effect on labor supply when the substitution and income effects of wage rate cancel each other. It is important to emphasize that a central finding in the empirical labor market literature is that labor supply tends to be quite unresponsive along the intensive margin (see for empirical evidence, e.g. Immervoll, Kleven, Kreiner and Saez

\footnotetext{
7 For a seminal paper about tax progression, see Musgrave and Thin (1948), and for another elaboration, see e.g. Lambert (2001, chapters 7-8).
} 
(2007) and Blundell and MaCurdy (1999)). Therefore, we focus on this finding concerning the market equilibrium of high-skilled workers.

\section{III.2.2 Market Equilibrium for High-Skilled Wage Formation}

Unlike in the case of low-skilled workers we assume that the high-skilled wage $w_{H}$ is determined by the market equilibrium concerning the equality of the labour demand function and the labor supply function. In the case of Cobb-Douglas utility function the equality $H^{*}=H^{s}$ gives $\frac{m a}{1-a} w_{H}^{-\varepsilon_{H}^{H}} W_{L}^{-\varepsilon_{L}^{H}}(1+s)^{-\frac{\varepsilon}{\varepsilon_{H}^{H}}}=\mu$, so that

$$
w_{H}=\left[\frac{\mu(1-a)}{m a}\right]^{-\frac{1}{\varepsilon_{H}^{H}}} w_{L}^{-\frac{\varepsilon_{L}^{H}}{\varepsilon_{H}^{H}}}(1+s)^{-\frac{\varepsilon}{\varepsilon_{H}^{H}}}
$$

where $\varepsilon_{L}^{H} / \varepsilon_{H}^{H}=\frac{\rho(1-a)}{1-\rho(1-a)}>0$ and $\varepsilon / \varepsilon_{H}^{H}=\frac{1}{1-\rho(1-a)}>1$. The comparative statics in terms of $w_{L}$ is

$$
\frac{\partial w_{H}}{\partial w_{L}}=-\frac{\varepsilon_{L}^{H}}{\varepsilon_{H}^{H}}\left[\frac{\mu(1-a)}{m a}\right]^{-\frac{1}{\varepsilon_{H}^{H}}} w_{L}^{-\frac{\varepsilon_{L}^{H}}{\varepsilon_{H}^{H}}-1}(1+s)^{-\frac{\varepsilon}{\varepsilon_{H}^{H}}}=-\frac{\varepsilon_{L}^{H}}{\varepsilon_{H}^{H}} \frac{w_{H}}{w_{L}}<0 .
$$

Equation (13) lies in conformity with empirics concerning the negative relationship between high-skilled and low-skilled wages. It has been empirically shown that higher outsourcing will decrease wage formation of low-skilled workers and increase wage formation of high-skilled workers, i.e. that wage dispersion will increase. ${ }^{8}$

The effect of payroll tax on the wage rate of high-skilled workers is under our utility assumption

\footnotetext{
${ }^{8}$ See evidence from various countries which lies in conformity with this, e.g. Braun and Scheffel (2007), Feenstra and Hanson (1999, 2001), Hijzen, Görg and Hine (2005), Hijzen (2007), Egger and Egger (2006), Munch and Skaksen (2005), Yan (2006), Riley and Young (2007) and Geishecker and Görg (2008).
} 


$$
\frac{\partial w_{H}}{\partial s}=-\frac{\varepsilon}{\varepsilon_{H}^{H}}\left[\frac{\mu(1-a)}{m a}\right]^{-\frac{1}{\varepsilon_{H}^{H}}} w_{L}^{-\frac{\varepsilon_{L}^{H}}{\varepsilon_{H}^{H}}}(1+s)^{-\frac{\varepsilon}{\varepsilon_{H}^{H}}-1}=-\frac{\varepsilon}{\varepsilon_{H}^{H}} \frac{w_{H}}{1+s}<0
$$

so that higher payroll tax will decrease the wage rate of high-skilled workers because it decreases labor demand (concerning empirical evidence, see. e.g. Daveri and Tabellini (2000), and Bingley and Lanot (2002)).

We can now summarize our findings regarding the properties of the high-skilled wage determination in the presence of outsourcing as follows.

\section{Proposition 2 In the presence of outsourcing}

(a) the high-skilled wage depends negatively on the low-skilled wage and the payroll tax, whereas

(b) the high-skilled wage is independent of the high-skilled wage tax parameters in the case of high-skilled workers' Cobb-Douglas utility function.

In the first sight, it may appear surprising that the high-skilled wage reacts negatively to the low-skilled wage tax, but is independent of the high-skilled wage tax rate. The intuition for this relies on our assumption that the high-skilled workers have a CobbDouglas utility function. With it, income and substitution effects of a tax increase on the labor supply cancel each other out.

\section{Wage Formation by Monopoly Labor Union for Low-Skilled Workers under Labor Taxation}

Now we analyze the wage formation of low-skilled workers and continue to consider the acquired amount of outsourcing, $M$ as given. We analyze the wage formation by the monopoly union (see also Cahuc and Zylberberg (2004), p. 401-403 concerning the monopoly union specification), which determines the wage for low- 
skilled workers in anticipation of optimal in-house low-skilled labor demand and of market equilibrium for the high-skilled wage $w_{H}{ }^{9}$

\section{IV.1. Wage Formation by the Monopoly Labor Union}

We investigate the wage formation by monopoly labor union when there is proportional payroll tax, and the linearly progressive wage tax for low-skilled workers. The market equilibrium for the high-skilled wage $w_{H}$ follows from the equality of labor demand and the labor supply by focusing on the case of Cobb-Douglas utility function. The monopoly labor union determines the wage for low-skilled workers in anticipation of optimal in-house employment decisions by the firm. We assume that the government can employ a proportional tax rate $t_{L}$, which is levied on the wage rate $w_{L}$

minus a tax exemption $e$. Thus the total tax base is $\left(w_{L}-e\right) L^{*}$. In the presence of a positive tax exemption the marginal wage tax exceeds the average wage tax rate $t_{L}\left(1-e / w_{L}\right)$ so that the system is linearly progressive. The net-of-tax wage is $\hat{w}_{L}=\left(1-t_{L}\right) w_{L}+t_{L} e$.

The objective function of the labor union is assumed to be $V=\left(\left(1-t_{L}\right) w_{L}+t_{L} e-b_{L}\right) L^{*}+b_{L} N=\left(\hat{w}_{L}-b_{L}\right) L^{*}+b_{L} N$, where $b_{L}$ is the (exogenous) outside option available to the low-skilled workers and $N$ is the number of labor union members. Given the amount of outsourcing, the monopoly labor union sets wage for the low-skilled workers so as to maximize the surplus according to

$$
\underbrace{\max }_{\left(w_{L}\right)} V=\left(\hat{w}_{L}-b_{L}\right) L^{*}+b_{L} N \quad \text { s.t. } \quad \pi_{L}=0 \text { and } H^{*}=H^{s}
$$

\footnotetext{
${ }^{9}$ In Western European countries, which are our focus, labor market institutions are close to this (see e.g. Freeman (2008).
} 
where $\quad H^{*}=\frac{m a}{1-a} w_{H}^{-\varepsilon_{H}^{H}} w_{L}^{-\varepsilon_{L}^{H}}(1+s)^{-\varepsilon} \quad$ and $\quad H^{s}=\mu$, which implies $w_{H}=\left[\frac{\mu(1-a)}{m a}\right]^{-\frac{1}{\varepsilon_{H}^{H}}} w_{L}^{-\frac{\varepsilon_{L}^{H}}{\varepsilon_{H}^{H}}}(1+s)^{-\frac{\varepsilon}{\varepsilon_{H}^{H}}}$ (see equations (10), (11) and (12)).

The first-order condition associated with (15) is

$$
V_{w_{L}}=\frac{L^{*}}{w_{L}}\left[\left(1-t_{L}\right) w_{L}+\left(\left(1-t_{L}\right) w_{L}+t_{L} e-b_{L}\right)\left(\frac{L_{w_{L}}^{*} w_{L}}{L^{*}}+\frac{L_{w_{H}}^{*} w_{H}}{L^{*}} \frac{\partial w_{H}}{\partial w_{L}} \frac{w_{L}}{w_{H}}\right)\right]=0 \text {. }
$$

This can be written as follows

$V_{w_{L}}=\left(1-t_{L}\right) w_{L}\left(1-\left(\hat{\varepsilon}_{L}^{L}+\hat{\varepsilon}_{H}^{L} \frac{\partial w_{H}}{\partial w_{L}} \frac{w_{L}}{w_{H}}\right)\right)+\left(b_{L}-t_{L} e\right)\left(\hat{\varepsilon}_{L}^{L}+\hat{\varepsilon}_{H}^{L} \frac{\partial w_{H}}{\partial w_{L}} \frac{w_{L}}{w_{H}}\right)=0$

where $\hat{\varepsilon}_{L}^{L}=\varepsilon_{L}^{L}\left(1+\frac{\gamma M}{L^{*}}\right)$ and $\hat{\varepsilon}_{H}^{L}=\varepsilon_{H}^{L}\left(1+\frac{\gamma M}{L^{*}}\right)$. These wage elasticities are not constant because the low-skilled labor demand, $L^{*}=m w_{L}^{-\varepsilon_{L}^{L}} w_{H}^{-\varepsilon_{H}^{L}}(1+s)^{-\varepsilon}-\gamma M$ depends negatively on the following variables: the high-skilled wage, the low-skilled wage, outsourcing, the productivity of the outsourced low-skilled labor input relative to the domestic low-skilled labor input, and the payroll tax. Equation (17) can be expressed as follows

$$
w_{L}^{*}=\left(\frac{\hat{\varepsilon}_{L}^{L}-\hat{\varepsilon}_{H}^{L} \frac{\varepsilon_{L}^{H}}{\varepsilon_{H}^{H}}}{\hat{\varepsilon}_{L}^{L}-\hat{\varepsilon}_{H}^{L} \frac{\varepsilon_{L}^{H}}{\varepsilon_{H}^{H}}-1}\right) \hat{b}_{L}=\left(\frac{\left(\varepsilon_{L}^{L}-\varepsilon_{H}^{L} \frac{\varepsilon_{L}^{H}}{\varepsilon_{H}^{H}}\right)\left(1+\gamma \frac{M}{L^{*}}\right)}{\left(\varepsilon_{L}^{L}-\varepsilon_{H}^{L} \frac{\varepsilon_{L}^{H}}{\varepsilon_{H}^{H}}\right)\left(1+\gamma \frac{M}{L^{*}}\right)-1}\right) \hat{b}_{L}
$$

where $\hat{b}_{L}=\frac{b_{L}-t_{L} e}{1-t_{L}}$. Therefore we have (see Appendix B)

$$
w_{L}^{*}\left(M, w_{H}, \gamma, t_{L}, e, b_{L}, s\right)=\left(\frac{\bar{\varepsilon}_{L}^{L}}{\bar{\varepsilon}_{L}^{L}-1}\right) \hat{b}_{L}=\frac{\beta\left(L^{*}+\gamma M\right)}{\left.(\beta-1) L^{*}+\beta \gamma M\right)} \hat{b}_{L}
$$


where the total wage elasticity allowing for the relationship between high-skilled and low-skilled wages is $\bar{\varepsilon}_{L}^{L}=\beta\left(1+\gamma \frac{M}{L^{*}}\right)>1, \quad \beta=\frac{1}{1-\rho(1-a)}$. It is important to emphasize that the optimal low-skilled wage (19) even for the monopoly labor union is an implicit form in the presence of outsourcing, because the mark-up $A=\frac{\beta\left(L^{*}+\gamma M\right)}{(\beta-1) L^{*}+\beta \gamma M}$ depends on the low-skilled wage rate in a non-linear way. It cannot be solved explicitly for the optimal domestic low-skilled wage.

\section{IV.2. Comparative Statics of Wage Formation}

In order to characterize the effect of outsourcing on the low-skilled wage formation we therefore apply the implicit differentiation. Differentiating the wage formation (19) with respect to low-skilled wage and outsourcing gives

$$
\left(1-\frac{\left[\left(\bar{\varepsilon}_{L}^{L}-1\right) \frac{\partial \bar{\varepsilon}_{L}^{L}}{\partial w_{L}}-\bar{\varepsilon}_{L}^{L} \frac{\partial \bar{\varepsilon}_{L}^{L}}{\partial w_{L}}\right]}{\left(\bar{\varepsilon}_{L}^{L}-1\right)^{2}} \hat{b}_{L}\right) d w_{L}^{*}=\frac{\left[\left(\bar{\varepsilon}_{L}^{L}-1\right) \frac{\partial \bar{\varepsilon}_{L}^{L}}{\partial M}-\bar{\varepsilon}_{L}^{L} \frac{\partial \bar{\varepsilon}_{L}^{L}}{\partial M}\right]}{\left(\bar{\varepsilon}_{L}^{L}-1\right)^{2}} \hat{b}_{L} d M
$$

which can be expressed as $\frac{d w_{L}^{*}}{d M}=-\frac{\frac{\partial \bar{\varepsilon}_{L}^{L}}{\partial M}}{\left(\bar{\varepsilon}_{L}^{L}-1\right)^{2}} \hat{b}_{L} /\left(1+\frac{\frac{\partial \bar{\varepsilon}_{L}^{L}}{\partial w_{L}}}{\left(\bar{\varepsilon}_{L}^{L}-1\right)^{2}} \hat{b}_{L}\right)<0$. Using equation $\hat{b}_{L}=\frac{w_{L}\left(\bar{\varepsilon}_{L}^{L}-1\right)}{\bar{\varepsilon}_{L}^{L}}, \quad \frac{\partial \bar{\varepsilon}_{L}^{L}}{\partial M}=\beta \frac{\gamma}{L^{*}}\left(1+\gamma \frac{M}{L^{*}}\right)=\frac{\gamma}{L^{*}} \bar{\varepsilon}_{L}^{L}>0$, and $\frac{\partial \bar{\varepsilon}_{L}^{L}}{\partial w_{L}}=\beta \gamma \frac{M}{w_{L} L^{*}} \varepsilon_{L}^{L}\left(1+\gamma \frac{M}{L^{*}}\right)=\varepsilon_{L}^{L} \frac{\gamma M}{w_{L} L^{*}} \bar{\varepsilon}_{L}^{L}>0$ the relationship between the low-skilled wage formation and outsourcing can be written as follows

$$
\frac{d w_{L}^{*}}{d M}=-\frac{w_{L}^{*} \frac{\gamma}{L^{*}}}{\bar{\varepsilon}_{L}^{L}-1+\gamma \frac{M}{L^{*}} \varepsilon_{L}^{L}}=-\frac{w_{L}^{*} \gamma}{(\beta-1) L^{*}+(1+\beta) \varepsilon_{L}^{L} \gamma M}<0
$$


so that higher outsourcing will decrease the wage of low-skilled workers. This lies in conformity with empirics.

Differentiating the implicit wage formation (19) with respect to the productivity of the outsourced low-skilled labor input relative to the domestic low-skilled labor input and low-skilled wage formation gives

$$
\left(1-\frac{\left[\left(\bar{\varepsilon}_{L}^{L}-1\right) \frac{\partial \bar{\varepsilon}_{L}^{L}}{\partial w_{L}}-\bar{\varepsilon}_{L}^{L} \frac{\partial \bar{\varepsilon}_{L}^{L}}{\partial w_{L}}\right]}{\left(\bar{\varepsilon}_{L}^{L}-1\right)^{2}} \hat{b}_{L}\right) d w_{L}^{*}=\frac{\left[\left(\bar{\varepsilon}_{L}^{L}-1\right) \frac{\partial \bar{\varepsilon}_{L}^{L}}{\partial \gamma}-\bar{\varepsilon}_{L}^{L} \frac{\partial \bar{\varepsilon}_{L}^{L}}{\partial \gamma}\right]}{\left(\bar{\varepsilon}_{L}^{L}-1\right)^{2}} \hat{b}_{L} d \gamma
$$

and can be expressed by using $\frac{\partial \bar{\varepsilon}_{L}^{L}}{\partial \gamma}=\beta\left[\frac{L^{*} M-\gamma M L_{\gamma}^{*}}{L^{* 2}}\right]=\frac{M}{L^{*}} \beta\left(1+\gamma \frac{M}{L^{*}}\right)=\frac{M}{L^{*}} \bar{\varepsilon}_{L}^{L}>0$

$$
\frac{d w_{L}^{*}}{d \gamma}=-\frac{w_{L}^{*} \frac{M}{L^{*}}}{\left[\bar{\varepsilon}_{L}^{L}-1+\gamma \frac{M}{L^{*}} \varepsilon_{L}^{L}\right]}=-\frac{w_{L}^{*} M}{(\beta-1) L^{*}+(1+\beta) \varepsilon_{L}^{L} \gamma M}<0 .
$$

Higher productivity of the outsourced low-skilled labor input relative to the domestic low-skilled labor input will have a wage moderating effect concerning low-skilled workers' wage. Moreover, and importantly, equations (21) and (23) jointly with equation (13) imply $\frac{d w_{H}^{*}}{d M}>0$ and $\frac{d w_{H}^{*}}{d \gamma}>0$ so that higher outsourcing and higher productivity of the outsourced low-skilled labor input will have positive effects on the domestic high-skilled labor wage.

In terms of comparative statics of wage tax, tax exemption and outside option we have (see Appendix B)

$$
\frac{d w_{L}^{*}}{d t_{L}}=\left(\frac{\bar{\varepsilon}_{L}^{L}}{\bar{\varepsilon}_{L}^{L}-1+\gamma \frac{M}{L^{*}} \varepsilon_{L}^{L}}\right) \frac{b_{L}-e}{\left(1-t_{L}\right)^{2}}=\frac{\beta\left(L^{*}+\gamma M\right)}{(\beta-1) L^{*}+(1+\beta) \varepsilon_{L}^{L} \gamma M} \frac{b_{L}-e}{\left(1-t_{L}\right)^{2}}>0 \text { as } b_{L}-e>0
$$




$$
\begin{aligned}
& \frac{d w_{L}^{*}}{d e}=-\left(\frac{\bar{\varepsilon}_{L}^{L}}{\bar{\varepsilon}_{L}^{L}-1+\gamma \frac{M}{L^{*}} \varepsilon_{L}^{L}}\right) \frac{t_{L}}{\left(1-t_{L}\right)}=-\frac{\beta\left(L^{*}+\gamma M\right)}{(\beta-1) L^{*}+(1+\beta) \varepsilon_{L}^{L} \gamma M} \frac{t_{L}}{\left(1-t_{L}\right)}<0 \\
& \frac{d w_{L}^{*}}{d b_{L}}=\left(\frac{\bar{\varepsilon}_{L}^{L}}{\bar{\varepsilon}_{L}^{L}-1+\gamma \frac{M}{L^{*}} \varepsilon_{L}^{L}}\right) \frac{1}{\left(1-t_{L}\right)}=\frac{\beta\left(L^{*}+\gamma M\right)}{(\beta-1) L^{*}+(1+\beta) \varepsilon_{L}^{L} \gamma M} \frac{1}{\left(1-t_{L}\right)}>0
\end{aligned}
$$

According to (24a-24c) the effects of wage tax, tax exemption and outside option on low-skilled wage formation are qualitatively the same with and without outsourcing because $\left.\quad \frac{d w_{L}^{*}}{d t_{L}}\right|_{M=0}=\frac{\beta}{(\beta-1)} \frac{b_{L}-e}{\left(1-t_{L}\right)^{2}}>0,\left.\quad \frac{d w_{L}^{*}}{d e}\right|_{M=0}=-\frac{\beta}{(\beta-1)} \frac{t_{L}}{\left(1-t_{L}\right)}<0 \quad$ and $\left.\frac{d w_{L}^{*}}{d b_{L}}\right|_{M=0}=\frac{\beta}{(\beta-1)} \frac{1}{\left(1-t_{L}\right)}>0$. Of course, in the absence of outsourcing the mark-up between outside option and wage formation $\left.A\right|_{M=0}=\frac{\beta}{\beta-1}=\frac{1}{\rho(1-a)}>1$ is higher than in the presence of outsourcing. Therefore the effects of wage tax, tax exemption and outside option for unemployment benefit are smaller in the presence of international outsourcing. Therefore, equations (24a-c) imply jointly with equation (13) that $\frac{d w_{H}^{*}}{d t_{L}}<0, \frac{d w_{H}^{*}}{d e}>0$ and $\frac{d w_{H}^{*}}{d b_{L}}<0$.

Finally, differentiating the implicit wage formation (19) with respect to the wage of low-skilled workers and the payroll tax gives

$$
\left(1-\frac{\left[\left(\bar{\varepsilon}_{L}^{L}-1\right) \frac{\partial \bar{\varepsilon}_{L}^{L}}{\partial w_{L}}-\bar{\varepsilon}_{L}^{L} \frac{\partial \bar{\varepsilon}_{L}^{L}}{\partial w_{L}}\right]}{\left(\bar{\varepsilon}_{L}^{L}-1\right)^{2}} \hat{b}_{L}\right) d w_{L}^{*}=\frac{\left[\left(\bar{\varepsilon}_{L}^{L}-1\right) \frac{\partial \bar{\varepsilon}_{L}^{L}}{\partial s}-\bar{\varepsilon}_{L}^{L} \frac{\partial \bar{\varepsilon}_{L}^{L}}{\partial s}\right]}{\left(\bar{\varepsilon}_{L}^{L}-1\right)^{2}} \hat{b}_{L} d s,
$$

which can be expressed as follows 


$$
\frac{d w_{L}^{*}}{d s}=-\frac{w_{L}^{*} \frac{\varepsilon \gamma M}{L^{*}(1+s)}}{\left[\bar{\varepsilon}_{L}^{L}-1+\gamma \frac{M}{L^{*}} \varepsilon_{L}^{L}\right]}=-\frac{w_{L}^{*} \varepsilon \gamma M}{(1+s)\left[(\beta-1) L^{*}+(1+\beta) \varepsilon_{L}^{L} \gamma M\right]}<0
$$

where $\frac{\partial \bar{\varepsilon}_{L}^{L}}{\partial s}=\frac{\beta \gamma M}{L^{*}(1+s)}\left(-\frac{L_{s}^{*}(1+s)}{L^{*}}\right)=\frac{\varepsilon}{(1+s)} \frac{\gamma M}{L^{*}} \bar{\varepsilon}_{L}^{L}>0$. Therefore, the payroll tax will have a wage moderating effect concerning the low-skilled workers' wage, because the payroll tax will have a positive effect on the wage elasticity. But in the absence of outsourcing it will have no effect because $\left.\frac{\partial \bar{\varepsilon}_{L}^{L}}{\partial s}\right|_{M=0}=0$.

The total effect of the payroll tax on the high-skilled workers' wage is the following

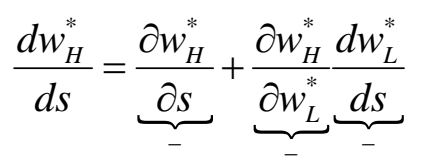

and using equations (13), (14) and (26) this can be expressed as

$$
\begin{aligned}
\frac{d w_{H}^{*}}{d s} & =-\frac{\varepsilon}{\varepsilon_{H}^{H}} \frac{w_{H}^{*}}{(1+s)}+\frac{\varepsilon_{L}^{H}}{\varepsilon_{H}^{H}} \frac{w_{H}^{*} \varepsilon \gamma M}{(1+s)\left[(\beta-1) L^{*}+(1+\beta) \varepsilon_{L}^{L} \gamma M\right]} \\
& =-\frac{\varepsilon w_{H}^{*}}{\varepsilon_{H}^{H}(1+s)}\left[1-\frac{\varepsilon_{L}^{H} \gamma M}{\left[(\beta-1) L^{*}+(1+\beta) \varepsilon_{L}^{L} \gamma M\right]}\right] \\
& \left.=-\frac{w_{H}^{*} \varepsilon}{\varepsilon_{H}^{H}(1+s)\left[(\beta-1) L^{*}+(1+\beta) \varepsilon_{L}^{L} \gamma M\right]}\left((\beta-1) L^{*}+\left((1+\beta) \varepsilon_{L}^{L}-\varepsilon_{L}^{H}\right)\right) \gamma M\right)<0
\end{aligned}
$$

which is also negative because $(\beta-1) L^{*}+\left((1+\beta) \varepsilon_{L}^{L}-\varepsilon_{L}^{H}\right) \gamma M>0$, where $(1+\beta) \varepsilon_{L}^{L}-\varepsilon_{L}^{H}=\varepsilon_{L}^{L}-\varepsilon_{L}^{H}+\beta \varepsilon_{L}^{L}=1+\beta \varepsilon_{L}^{L}>0$.

We can now summarize our findings in terms of the low-skilled wage formation in the presence of outsourcing as follows. 


\section{Proposition 3 In the presence of outsourcing}

(a) the higher level of outsourced production and the higher productivity of outsourced production will decrease the wage for the low-skilled labor and increase the wage for the high-skilled labor, thereby inducing higher wage dispersion, and

(b) the higher low-skilled wage tax will increase the wage for the low-skilled labor and decrease the wage for high-skilled labor and the higher lowskilled wage tax exemption will decrease the wage for the low-skilled labor and will increase the wage for the high-skilled labor, and these qualitative results are also similar but larger in the absence of outsourcing, and

(c) the higher payroll tax for the firms will decrease the wage for the lowskilled and high-skilled labor. In the absence of outsourcing, the higher payroll tax for the firms will decrease the wage for the high-skilled labor, but has no effect on the wage of low-skilled labor.

The first part of Proposition 3 reveals political economy considerations related to outsourcing and taxation. An increased outsourcing benefits high-skilled workers, but hurts low-skilled workers. Such a result is perfectly in line with the fact that the outsourced input is a substitute to the low-skilled labor, and a complement to highskilled labor. Nonetheless, the conventional analysis has focused on competitive labor markets.

The second part of Proposition 3 reports that the qualitative effects of wage taxes and tax exemption for the low-skilled workers are not changed by outsourcing. A higher wage tax for the low-skilled labor will encourage labor unions to increase their wage demand, which pushes for higher low-skilled unemployment and lower highskilled wages. A higher tax exemption for the low-skilled, on the other hand, reduces the wage demand by the labor union. This results in a lower unemployment for the lowskilled, and increases the wages for the high-skilled.

The third part of Proposition 3 reveals that outsourcing may change qualitatively how wage demands by labor unions respond to payroll taxes. In the absence of 
outsourcing, a higher payroll tax has no effect on the wage of low-skilled labor that the labor unions set. With outsourcing, labor unions cut their wage demand when the payroll tax is increased. The wage for the high-skilled is decreasing in the payroll tax rate, both with and without outsourcing.

\section{Optimal Committed Outsourcing Before Wage Formation and Domestic Labor Demand}

We now turn to explore the stage, where the firm commits itself to the outsourcing activity $M$ prior to the determination of wages and domestic employment. We characterize how tax parameters affect the equilibrium production mode. It is assumed that the long-run production mode decision internalizes the effect of the share of outsourced production on the low-skilled wage and also on the high-skilled wage.

The firm determines the magnitude of outsourcing so as to maximize its profit. It is assumed that the firm has rational expectations regarding the subsequent outcomes with respect to the high-skilled and low-skilled wage and employment so that the production mode internalizes the effects of the share of outsourced production on wages and employment. The production mode is determined by the following optimization problem in the presence of linearly progressive wage taxation and proportional payroll taxation

$$
\begin{aligned}
& \underbrace{\operatorname{Max}}_{(M)} \pi=\left[H^{* a}\left(L^{*}+\lambda M\right)^{1-a}\right]^{\rho}-\widetilde{w}_{H} H^{*}-\widetilde{w}_{L} L^{*}-0.5 c M^{2} \\
& \text { s.t. } V_{L}=0, \pi_{L}=0 \text { and } H^{*}=H^{s}
\end{aligned}
$$

where $\left[H^{* a}\left(L^{*}+\lambda M\right)^{1-a}\right]^{\rho}=F, \quad \widetilde{w}_{H}=(1+s) w_{H}$ and $\widetilde{w}_{L}=(1+s) w_{L}$. By applying the envelope theorem we get the following first-order condition for the optimal amount of committed outsourcing associated with the optimization problem (29) by taking tax 
parameters as given ${ }^{10}$

$$
\pi_{M}=F_{M} \underbrace{\frac{d w_{L}^{*}}{d M}(1+s) L^{*}}_{+}-\underbrace{\frac{\partial w_{H}^{*}}{\partial w_{L}^{*}} \frac{d w_{L}^{*}}{d M}(1+s) H^{*}}_{-}-c M=0
$$

where $\frac{d w_{L}^{*}}{d M}=-\frac{w_{L}^{*} \gamma}{(\beta-1) L^{*}+(1+\beta) \varepsilon_{L}^{L} \gamma M}<0$ (see equation 21) and

$$
F_{M}=\gamma F_{L}=\gamma(1+s) w_{L}^{*}
$$

and

$$
\frac{\partial w_{H}^{*}}{\partial w_{L}^{*}} \frac{d w_{L}^{*}}{d M}=\frac{\varepsilon_{L}^{H}}{\varepsilon_{H}^{H}} \frac{w_{H}^{*} \frac{\gamma}{L^{*}}}{\left[\bar{\varepsilon}_{L}^{L}-1+\gamma \frac{M}{L^{*}} \varepsilon_{L}^{L}\right]}=\frac{\varepsilon_{L}^{H}}{\varepsilon_{H}^{H}} \frac{w_{H}^{*} \gamma}{(\beta-1) L^{*}+(1+\beta) \varepsilon_{L}^{L} \gamma M}>0 .
$$

Hence, outsourcing has both direct and indirect effects. The direct effects of an increase in outsourcing are the direct marginal cost $c M$ and the direct marginal profit $F_{M}$. The indirect effects are that outsourcing decreases the wage cost of the domestic low-skilled labor, because these are substitutes, but increases the market equilibrium wage cost of domestic high-skilled labor, because these are complements. Therefore, according to (30) the presence of domestic labor market imperfection increases the returns from outsourcing because it has an aggregate wage-moderating effect, but also decreases the returns due to wage increase of high-skilled labor. ${ }^{11}$

The first-order condition (30) we can now re-express it in the following way (see Appendix C)

$$
\pi_{M}=\frac{\gamma \varepsilon_{L}^{L}(1+s) w_{L}^{*}}{\varepsilon_{H}^{H}}\left(\frac{L^{*}+g \gamma M}{(\beta-1) L^{*}+(1+\beta) \varepsilon_{L}^{L} \gamma M}\right)-c M=0
$$

\footnotetext{
${ }^{10}$ Outsourcing does not have a direct effect on the high-skilled wage, but only via the effect of lowskilled wage, see equation (12).

${ }^{11}$ This lies in conformity with empirics, see e.g. Braun and Scheffel (2007), Egger and Egger (2006), Feenstra and Hanson (1999, 2001), Hijzen, Görg and Hine (2005), Geishecker and Görg (2008), Hijzen (2007), and Munch and Skaksen (2005).
} 
where $g=(1+\beta) \varepsilon_{H}^{H}-\varepsilon_{H}^{L} / \varepsilon_{L}^{L}>0$.

Now we analyze the effects of wage tax, tax exemption, unemployment benefit as well as the effect of payroll tax on the optimal outsourcing. Using the notation $(\beta-1) L^{*}+(1+\beta) \varepsilon_{L}^{L} \gamma M=X \quad$ the second-order condition is $\pi_{M M}=-\frac{\gamma^{2} \varepsilon_{L}^{L}(1+s) w_{L}^{*}}{\varepsilon_{H}^{H} X^{2}}\left[L^{*}\left((1+\beta)-\frac{\varepsilon_{L}^{H} \varepsilon_{H}^{L}}{\varepsilon_{L}^{L} \varepsilon_{H}^{H}}\right)\right)+\gamma M\left(g(2-\beta)+(1+\beta) \varepsilon_{L}^{L}\right]-c<0 . \quad$ This can be written as

$$
\pi_{M M}=-\frac{\gamma^{2} \varepsilon_{L}^{L}(1+s) w_{L}^{*}}{\varepsilon_{H}^{H} M X^{2}} Z<0
$$

where $Z>0$ (see Appendix C).

In terms of the wage tax rate $t_{L}$ the first-order condition (32) changes as

$$
\begin{aligned}
\pi_{M t_{L}} & =\frac{\gamma \varepsilon_{L}^{L}}{\varepsilon_{H}^{H}}(1+s) \frac{d w_{L}^{*}}{d t_{L}}\left(\frac{L^{*}+g \gamma M}{X}\right)+ \\
& \frac{\gamma \varepsilon_{L}^{L}}{\varepsilon_{H}^{H}}(1+s) w_{L}^{*}\left(\frac{X-\left(L^{*}+g \gamma M\right)(\beta-1)}{X^{2}}\right) L_{w_{L}^{*}}^{*} \frac{d w_{L}^{*}}{d t_{L}}
\end{aligned}
$$

Using $L_{w_{L}^{*}}^{*}=-\frac{\varepsilon_{L}^{L}\left(L^{*}+\gamma M\right)}{w_{L}^{*}}$, (34) can be written (see equation (24a) and Appendix C)

$$
\pi_{M t_{L}}=\frac{\gamma \varepsilon_{L}^{L}(1+s)}{\varepsilon_{H}^{H} X^{2}} \underbrace{\frac{d w_{L}^{*}}{d t_{L}}}_{+} T>0 \quad \text { as } \quad b_{L}-e>0
$$

where $T=X\left(L^{*}+g \gamma M\right)-\left(X-\left(L^{*}+g \gamma M\right)(\beta-1)\right) \varepsilon_{L}^{L}\left(L^{*}+\gamma M\right)>0$. Using (33) and (35) we have

$$
\frac{\partial M}{\partial t_{L}}=-\frac{\pi_{M t_{L}}}{\pi_{M M}}=\underbrace{\frac{d w_{L}^{*}}{d t_{L}}}_{+} \frac{M}{w_{L}^{*} \gamma} \frac{T}{Z}>0 \text { as } b_{L}-e>0 .
$$

In terms of tax exemption and higher unemployment benefit we will get in the similar way the following results: By using the cross-derivative for tax exemption $\pi_{M e}=\frac{\gamma \varepsilon_{L}^{L}(1+s)}{\varepsilon_{H}^{H} X^{2}} \underbrace{\frac{d w_{L}^{*}}{d e}} T<0$ gives (see equation (24b) and Appendix C) 


$$
\frac{\partial M}{\partial e}=-\frac{\pi_{M e}}{\pi_{M M}}=\underbrace{\frac{d w_{L}^{*}}{d e}}_{-} \frac{M}{w_{L}^{*} \gamma} \frac{T}{Z}<0
$$

and using the cross-derivative $\pi_{M b_{L}}=\frac{\gamma \varepsilon_{L}^{L}(1+s)}{\varepsilon_{H}^{H} X^{2}} \underbrace{\frac{d w_{L}^{*}}{d b_{L}}}_{+} T>0$ gives

$$
\frac{\partial M}{\partial b_{L}}=-\frac{\pi_{M b_{L}}}{\pi_{M M}}=\underbrace{\frac{d w_{L}^{*}}{d b_{L}}}_{+} \frac{M}{w_{L}^{*} \gamma} \frac{T}{Z}>0
$$

Therefore, both higher domestic low-skilled wage tax and higher unemployment benefit increase optimal outsourcing, while higher tax exemption, ceteris paribus, decreases optimal outsourcing, when we have also allowed the effects of these policy parameters via the wage of the high-skilled workers.

In terms of payroll tax rate $s$ the first-order condition (32) will change via different aspects in the following way:

$$
\begin{aligned}
\pi_{M s}= & \frac{\gamma \varepsilon_{L}^{L}}{\varepsilon_{H}^{H}}\left(w_{L}^{*}+(1+s) \frac{d w_{L}^{*}}{d s}\right)\left(\frac{L^{*}+g \gamma M}{X}\right)+ \\
& \frac{\gamma \varepsilon_{L}^{L}(1+s) w_{L}^{*}}{\varepsilon_{H}^{H}} \frac{\left[X-\left(L^{*}+g \gamma M\right)(\beta-1)\right]}{X^{2}}\left(L_{w_{L}^{*}}^{*} \frac{d w_{L}^{*}}{d s}+L_{s}^{*}\right)
\end{aligned}
$$

which can be expressed as follows (see equations (C8) and (C9) in Appendix C)

$$
\pi_{M s}=\underbrace{\frac{\gamma \varepsilon_{L}^{L} w_{L}^{*}}{\varepsilon_{H}^{H} X^{2}}}_{+}\left(\left[\left(L^{*}+g \gamma M\right)(X-\varepsilon \gamma M)\right]-\left[1-\frac{\left(L^{*}+g \gamma M\right)(\beta-1)}{X}\right]\left[\varepsilon\left(L^{*}+\gamma M\right)\left(X-\varepsilon_{L}^{L} \gamma M\right)\right]\right) .
$$

By using the cross-derivative $\pi_{M s}$ gives

$$
\frac{\partial M}{\partial s}=-\frac{\pi_{M s}}{\pi_{M M}}=\frac{M}{(1+s) \gamma} \frac{J}{Z}
$$


where $\quad J=\left[\left(L^{*}+g \gamma M\right)(X-\varepsilon \gamma M)\right]-\left[1-\frac{\left(L^{*}+g \gamma M\right)(\beta-1)}{X}\right]\left[\varepsilon\left(L^{*}+\gamma M\right)\left(X-\varepsilon_{L}^{L} \gamma M\right)\right]$, and $\quad\left[1-\frac{\left(L^{*}+g \gamma M\right)(\beta-1)}{X}\right]=\frac{\gamma M}{X}\left((1+\beta) \varepsilon_{L}^{L}-(\beta-1) g\right)<1 \quad$ because $(1+\beta) \varepsilon_{L}^{L}>(\beta-1) g$. The sign of $J$ is a priori ambiguous so that higher payroll tax has an ambiguous effect on optimal outsourcing.

We can now summarize our findings in terms of optimal outsourcing as follows:

Proposition 4 Optimal committed outsourcing will be affected by the policy parameters as follows

(a) the higher domestic low-skilled wage tax and the higher unemployment benefit increase optimal outsourcing, while the higher tax exemption, ceteris paribus, decreases optimal outsourcing, whereas

(b) the higher payroll tax for the firms has an ambiguous effect on optimal outsourcing.

Proposition 4 reports that in the presence of outsourcing, higher marginal tax on the low-skilled workers tends to increase optimal outsourcing. The same holds for a higher unemployment benefit, while higher tax exemption on the low-skilled labor decreases outsourcing. The intuition for these results is the following: In the absence of a change in outsourcing, higher marginal tax rate, higher unemployment benefit, or lower tax exemption would each encourage the labor union to increase its wage demand. This would, in turn, increase the optimal level of outsourcing. Anticipating the policy response by the labor unions, firms increase the amount of outsourcing. If payroll tax changes, the amount of outsourcing might increase or decrease. ${ }^{12}$

\footnotetext{
${ }^{12}$ It is an important further topic to check via numerical simulations, when this effect is positive or negative and how it depends on the precise parameter values.
} 


\section{Determinants of Equilibrium Unemployment by Low-Skilled Workers}

\section{VI.1. Outsourcing and Equilibrium Unemployment}

We now move on to explore the determinants of equilibrium unemployment of low-skilled workers in dual labor markets, when there is both unionized and competitive determination of wages in the home country. First we analyze the effect of outsourcing given labor tax parameters and study the effects of labor taxation parameters on equilibrium unemployment both via wage and outsourcing changes. According to (19) the wage formation for low-skilled workers in industry $i$ is of the form $w_{L}^{*}=A \hat{b}_{L}$, where $\hat{b}_{L}=\frac{b_{L}-t_{L} e}{1-t_{L}}$ is in the presence of linearly progressive wage taxation and the mark-up factor $A=\frac{\beta\left(L^{*}+\gamma M\right)}{(\beta-1) L^{*}+\beta \gamma M}>1$. This mark-up factor is, in principle, industry-specific. In a general equilibrium the term $b_{L}$ should be reinterpreted as the endogenous outside option, which we specify as ${ }^{13}$

$$
b_{L}=(1-u) w_{L}+u_{L} \bar{b}_{L}
$$

where $u_{L}$ is the unemployment rate, $\bar{b}_{L}$ captures the unemployment benefit and $w_{L}$ denotes the wage formation in all identical industries (see e.g. Nickell and Layard (1999), p. 3048-3049 for a further discussion). Assuming a constant benefitreplacement ratio $0<q=\bar{b}_{L} / w_{L}^{*}<1$ so that by using (41) we have $\hat{b}_{L}=\frac{b_{L}-t_{L} e}{1-t_{L}}=\frac{w_{L}^{*}+u_{L}(q-1) w_{L}^{*}-t_{L} e}{1-t_{L}}$ and $w_{L}^{*}=A \hat{b}_{L} \quad$ can be written as

\footnotetext{
${ }^{13}$ This approach for endogenous outside option has been used also in a dynamic model by Koskela and von Thadden (2008).
} 
$\left(1-t_{L}\right) w_{L}^{*}=A\left(w_{L}^{*}-t_{L} e\right)+A u_{L}(q-1) w_{L}^{*}$ and in this case the equilibrium low-skilled unemployment can be presented

$$
u_{L}=\frac{1}{(1-q)}\left(\frac{A-1+t_{L}\left(1-\frac{A e}{w_{L}^{*}}\right)}{A}\right)=\frac{1}{(1-q)} G
$$

where $\quad G \equiv\left(1-\frac{1}{A} \frac{b_{L}\left(1-t_{L}\right)}{\left(b_{L}-t_{L} e\right)}\right)$. Higher benefit-replacement ratio will increase equilibrium unemployment. According to (42) in the presence of a constant benefitreplacement ratio $q=\bar{b}_{L} / w_{L}^{*}$ the impact of outsourcing on equilibrium unemployment under both progressive wage taxation and proportional payroll labor taxation comes via the mark-up $A=\frac{\beta\left(L^{*}+\gamma M\right)}{(\beta-1) L^{*}+\beta \gamma M}$ in (42). In the presence of outsourcing the mark-up depends positively on low-skilled labor demand, i.e. $A_{L}=\frac{\beta \gamma M}{\left[(\beta-1) L^{*}+\beta \gamma M\right]^{2}}>0$, and negatively on outsourcing, i.e. $\left.A_{M}=-\frac{\gamma A}{\left[(\beta-1) L^{*}+\beta \gamma M\right.}\right]^{<0}$.

In terms of outsourcing we have

$$
\frac{d G}{d M}=\underbrace{\frac{d A}{d M}}_{-} \underbrace{\left(\frac{b_{L}\left(1-t_{L}\right)}{\left(b_{L}-t_{L} e\right)}\right)}_{+}<0
$$

where outsourcing will have both the direct negative effect and the indirect positive effect via the wage on the total mark-up, but the direct effect dominates as

$$
\begin{aligned}
& \left.\frac{d A}{d M}=A_{M}+A_{w_{L}^{*}} \frac{d w_{L}^{*}}{d M}=-\frac{\gamma A}{\left[(\beta-1) L^{*}+\beta \gamma M\right.}\right]\left(1-\frac{\varepsilon_{L}^{L} \gamma M}{(\beta-1) L^{*}+(1+\beta) \varepsilon_{L}^{L} \gamma M}\right)<0 \quad \text { by using } \\
& A_{M}=-\frac{\gamma A}{\left[(\beta-1) L^{*}+\beta \gamma M\right]}<0, \quad A_{w_{L}^{*}}=-\frac{\varepsilon_{L}^{L} \gamma M A}{\left.w_{L}^{*}\left[(\beta-1) L^{*}+\beta \gamma M\right)\right]}<0 \quad \text { and } \\
& \frac{d w_{L}^{*}}{d M}=-\frac{w_{L}^{*} \gamma}{(\beta-1) L^{*}+(1+\beta) \varepsilon_{L}^{L} \gamma M}<0 \text { (see equations (19) and (21)). Therefore by }
\end{aligned}
$$


combining (43) and (42) gives $\frac{d u_{L}}{d M}=\frac{1}{1-q} \frac{d G}{d M}<0$ so that higher outsourcing also in the presence of progressive wage taxation and proportional payroll taxation will decrease equilibrium unemployment when the benefit-replacement ratio is fixed and less than one. We can now summarize this finding as

Proposition 5 A production mode with a higher amount of outsourced production, ceteris paribus, will reduce equilibrium unemployment of lowskilled workers both in the presence and in the absence of progressive wage taxation and proportional payroll taxation.

Proposition 5 reports very importantly the negative relationship between outsourcing and equilibrium unemployment of low-skilled workers, i.e. only concerning the relationship between higher wage elasticity of low-skilled labor demand and outsourcing, which leads to wage moderation of low-skilled workers and thereby smaller unemployment. Of course if there would be wage rigidity, then higher outsourcing would increase unemployment due to a decrease in domestic low-skilled labor demand.

\section{VI.2. Labor Tax Instruments and Equilibrium Unemployment}

Next we analyze the effect of labor tax parameters on equilibrium unemployment of low-skilled workers. According to Proposition 4 a higher domestic low-skilled wage tax, a higher unemployment benefit and a lower wage tax exemption increase optimal outsourcing, while the effects of a payroll tax on optimal outsourcing are ambiguous.

Following the time sequence of decisions, presented in Figure 1, the total wage effects of tax policy instruments consist both of the direct effects and of the indirect effects via the impact these instruments have on the strategic outsourcing decision of firms and thereby also on the wage rate. The total effect of the wage tax is 
$\frac{d w_{L}^{*}}{d t_{L}}=\underbrace{\frac{\partial w_{L}^{*}}{\partial t_{L}}}_{+}+\underbrace{\frac{\partial w_{L}^{*}}{\partial M} \frac{\partial M}{\partial t_{L}}}_{-}$. The direct wage effect is positive, and the indirect effect via outsourcing is negative, because the wage tax makes outsourcing more attractive which lowers the benefit of the wage increase for the monopoly labor union. By using equations (21), (24a) and (36) we can rewrite it as follows

$$
\frac{d w_{L}^{*}}{d t_{L}}=\frac{\partial w_{L}^{*}}{\partial t_{L}}+\frac{\partial w_{L}^{*}}{\partial M} \frac{\partial M}{\partial t_{L}}=\frac{\partial w_{L}^{*}}{\partial t_{L}}\left[1+\frac{\partial w_{L}^{*}}{\partial M} \frac{M T}{w_{L}^{*} \gamma Z}\right]=\underbrace{\frac{\partial w_{L}^{*}}{\partial t_{L}}}_{+}\left[1-\frac{M T}{X Z}\right]
$$

In what follows we assume that the direct effect dominates the indirect effect, which is a reasonable assumption. We make the same assumption also in the case of tax exemption $e$.

By differentiating the mark-up of (42) in terms of wage tax $t_{L}$ which gives via $w_{L}^{*}$ and $M$

$$
\frac{d G}{d t_{L}}=(\underbrace{\frac{d A}{d t_{L}}\left(\frac{\left(b_{L}\left(1-t_{L}\right)\right.}{A^{2}}\right)}_{-}+\underbrace{\frac{b_{L}\left(b_{L}-e\right)}{A\left(b_{L}-t_{L}-t_{L} e\right)}}_{+})=\text {? as } b_{L}>e
$$

where $\frac{d A}{d t_{L}}=\frac{\beta \gamma M L_{w_{L}^{*}}^{*} \frac{d w_{L}^{*}}{d t_{L}}-\beta \gamma\left(L^{*}+\gamma M\right) \frac{\partial M}{\partial t_{L}}}{\left[(\beta-1) L^{*}+\beta \gamma M\right]^{2}}=\frac{\beta \gamma\left(M L_{w_{L}^{*}}^{*} \frac{d w_{L}^{*}}{d t_{L}}-\left(L^{*}+\gamma M\right) \frac{\partial M}{d t_{L}}\right)}{\left[(\beta-1) L^{*}+\beta \gamma M\right]^{2}}<0$ as $b_{L}-e>0$ as $\frac{d w_{L}^{*}}{d t_{L}}=\underbrace{\frac{\partial w_{L}^{*}}{\partial t_{L}}}_{+}+\underbrace{\frac{\partial w_{L}^{*}}{\partial M} \frac{\partial M}{\partial t_{L}}}_{-}=\frac{\partial w_{L}^{*}}{\partial t_{L}}\left[1-\frac{M T}{X Z}\right]>0$. Therefore by combining (45) and (42) gives $\frac{d u_{L}}{d t_{L}}=\frac{1}{1-q} \frac{d G}{d t_{L}}=$ ? so that higher wage tax in the presence of outsourcing will have an ambiguous effect on equilibrium unemployment when the benefit-replacement ratio is fixed and less than one. This is because the total effect of higher wage tax on wage of low-skilled workers is negative and thereby increases the wage elasticity and lowers the mark-up because of lower labor demand and higher 
outsourcing. But there is also the positive direct effect of wage tax on $G$ due to $\frac{d}{d t_{L}}\left(\frac{b_{L}\left(1-t_{L}\right)}{b_{L}-t_{L} e}\right)<0$. In terms of tax exemption $e$ for low-skilled workers we have

$$
\frac{d G}{d e}=(\underbrace{\frac{d A}{A^{2}}\left(\frac{\left(b_{L}\left(1-t_{L}\right)\right.}{\left(b_{L}-t_{L} e\right)}\right)}_{+} \underbrace{\frac{t_{L}\left(b_{L}\left(1-t_{L}\right)\right)}{A\left(b_{L}-t_{L} e\right)^{2}}}_{-})=?
$$

where $\frac{d A}{d e}=\frac{\beta \gamma\left(M L_{w_{L}^{*}}^{*} \frac{d w_{L}^{*}}{d e}-\left(L^{*}+\gamma M\right) \frac{\partial M}{\partial e}\right)}{\left[(\beta-1) L^{*}+\beta \gamma M\right]^{2}}>0$ as

$\frac{d w_{L}^{*}}{d e}=\underbrace{\frac{\partial w_{L}^{*}}{\partial e}}_{-}+\underbrace{\frac{\partial w_{L}^{*}}{\partial M} \frac{\partial M}{\partial e}}_{+}=\frac{\partial w_{L}^{*}}{\partial e}\left[1-\frac{M T}{X Z}\right]<0$. Therefore by combining (46) and

gives $\frac{d u_{L}}{d e}=\frac{1}{1-q} \frac{d G}{d e}=$ ? so that higher tax exemption in the presence of outsourcing will also have an ambiguous effect on equilibrium unemployment. This is because the total effect of higher tax exemption on wage of low-skilled workers is positive and thereby decreases the wage elasticity and raises mark-up because of higher labor demand and lower outsourcing. But there is also the negative effect of tax exemption on $G$ due to $\frac{d}{d e}\left(\frac{\left(b_{L}\left(1-t_{L}\right)\right.}{b_{L}-t_{L} e}\right)>0$.

Finally, by differentiating the mark-up of (42) in terms of payroll tax $s$ gives

$$
\frac{d G}{d s}=\frac{\frac{d A}{d s}}{A^{2}}\left(\frac{b_{L}\left(1-t_{L}\right)}{\left(b_{L}-t_{L} e\right)}\right)=?
$$

where $\quad \frac{d A}{d s}=\frac{\beta \gamma\left(M\left(L_{w_{L}^{*}}^{*} \frac{d w_{L}^{*}}{d s}+L_{s}^{*}\right)-\left(L^{*}+\gamma M\right) \frac{\partial M}{\partial s}\right)}{\left[(\beta-1) L^{*}+\beta \gamma M\right]^{2}}=$ ?
$\frac{d w_{L}^{*}}{d s}=\underbrace{\frac{\partial w_{L}^{*}}{\partial s}}_{-}+\underbrace{\frac{\partial w_{L}^{*}}{\partial M} \frac{\partial M}{\partial s}}_{?}=$ ? (see Appendix C). Therefore, combining (47) and (42) gives 
$\frac{d u_{L}}{d s}=\frac{1}{1-q} \frac{d G}{d s}=$ ? so that higher payroll tax in the presence of outsourcing will have an ambiguous effect. It will decrease the low-skilled labor demand, but have an ambiguous indirect effect via higher outsourcing so that the mark-up effect is ambiguous.

We can summarize our findings in terms of the effect of tax parameters as.

Proposition 6 In the presence of outsourcing when the benefit-replacement ratio is fixed and less than one and concerning the assumption that the direct effects of tax parameters on wage formation dominate the indirect effect via outsourcing

(a) the higher wage tax and the higher tax exemption will have an ambiguous effect on equilibrium unemployment, as well as

(b) the higher payroll tax will also have an ambiguous effect on equilibrium unemployment because it will decrease the low-skilled labor demand but will have ambiguous effect on outsourcing.

Ambiguity associated with workers' taxation parameters is due to the facts that the total effect of higher wage tax (tax exemption) on wage of low-skilled workers is negative (positive) so that wage elasticity increases (decreases) and the mark-up lowers (raises), but there is also the positive (negative) direct effects of parameters. In the absence of

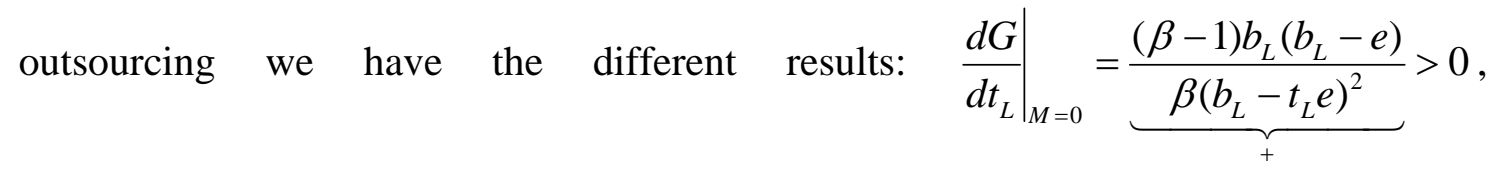
$\left.\frac{d G}{d e}\right|_{M=0}=-\underbrace{\frac{(\beta-1) t_{L} b_{L}\left(1-t_{L}\right)}{\beta\left(b_{L}-t_{L} e\right)^{2}}}_{+}<0$, and $\left.\frac{d G}{d s}\right|_{M=0}=0$. Therefore, the effects of tax parameters are as follows. 
Corollary In the absence of outsourcing

(a) the higher wage tax and the lower tax exemption will have a positive effect on equilibrium unemployment, while

(b) the higher payroll tax will have no effect.

\section{VI.3. Higher Degree of Tax Progression and the Low-Skilled Labor Demand}

Finally, we analyze the effect of wage tax progression on wage formation by the low-skilled workers and labor demand. We assume that the tax reform will keep the relative tax burden per low-skilled worker constant, i.e. this means

$$
t_{L}-\frac{t_{L} e}{w_{L}}=R
$$

The government can raise the degree of tax progression when it increases $t_{L}$ and $e$ such that $d R=0$. Formally we have by using equations (36) and (37)

$$
\left.\frac{d e}{d t_{L}}\right|_{d R=0}=\frac{\left(w_{L}^{*}-e+\frac{t_{L} e}{w_{L}} \frac{d w_{L}^{*}}{d t_{L}}\right)}{\left(t_{L}-\frac{t_{L} e}{w_{L}} \frac{d w_{L}^{*}}{d e}\right)}=\frac{\left(w_{L}^{*}-e+\frac{t_{L} e}{w_{L}} \frac{\partial w_{L}^{*}}{\partial t_{L}}(1-B)\right)}{\left(t_{L}-\frac{t_{L} e}{w_{L}} \frac{\partial w_{L}^{*}}{\partial e}(1-B)\right)}>0
$$

where $B=\frac{M T}{X Z}<1$. Concerning the low-skilled wage effect of this tax reform we have $d w_{L}^{*}=(1-B)\left[\frac{\partial w_{L}^{*}}{\partial t_{L}} d t_{L}+\frac{\partial w_{L}^{*}}{\partial e} d e\right]$ and dividing by $d t_{L}$ and substituting the RHS of (49) for $d e / d t_{L}$ gives (see Appendix D)

$$
\left.\frac{d w_{L}^{*}}{d t_{L}}\right|_{d R=0}=\frac{(1-B)\left[\frac{\partial w_{L}^{*}}{\partial t_{L}}+\frac{\left(w_{L}^{*}-e\right)}{t_{L}} \frac{\partial w_{L}^{*}}{\partial e}\right]}{\left[1-\frac{e}{w_{L}^{*}} \frac{\partial w_{L}^{*}}{\partial e}(1-B)\right]}<0
$$


so that a higher degree of tax progression, keeping the relative tax burden per worker constant, will decrease the low-skilled wage rate both in the presence and absence of outsourcing (when $B=0$ ). Finally, we characterize the low-skilled employment effect of this tax reform. By raising tax progression according to (49) we have $d L^{*}=L_{w_{L}^{*}}^{*}(1-B)\left[\frac{\partial w_{L}^{*}}{\partial t_{L}} d t_{L}+\frac{\partial w_{L}^{*}}{\partial e} d e\right]-\gamma\left[M_{t_{L}} d t_{L}+M_{e} d e\right]$ so that the first term indicates the effect on the wage rate on the low-skilled labor demand and the second term indicates the induced outsourcing. Dividing this by $d t_{L}$ and substituting the RHS of (49) for $d e / d t_{L}$ gives after calculations (see Appendix D)

$$
\left.\frac{d L^{*}}{d t_{L}}\right|_{d R=0}=\underbrace{\left.L_{w_{L}^{*}}^{*} \frac{d w_{L}^{*}}{d t_{L}}\right|_{d R=0}}_{+}-\gamma \underbrace{\left.\frac{d M}{d t_{L}}\right|_{d R=0}}_{-}>0
$$

so that a higher degree of tax progression, keeping the relative tax burden per worker constant, will increase the low-skilled labor demand both in the presence and absence of outsourcing (when the second term is zero).

We can now summarize our findings as follows.

Proposition 7 In the presence of outsourcing raising the wage tax and the tax exemption to keep the relative tax burden per worker constant, this higher degree of tax progression will decrease the wage rate and increase labor demand of low-skilled workers. This also works in the absence of outsourcing.

\section{Conclusions}

Most European countries are characterized by dual labor markets, in which wages of some workers are set by labor unions, while other wages are determined competitively. In this paper, we have studied how the presence of international outsourcing affects such an economy when the low-skilled workers are unionized, and the high-skilled workers are employed in competitive labor markets. We also examine 
how wage taxation and the payroll tax affect outsourcing decisions and subsequent wage formation.

We have shown that the own wage elasticity, the cross wage elasticity and the outsourcing elasticity for the low-skilled labor demand depend positively on the amount of outsourcing, and these also depend positively on the payroll tax. The own wage elasticity, the cross wage elasticity and the outsourcing elasticity for the high-skilled labor demand are independent of the amount of outsourcing and the payroll tax. In the presence of outsourcing the low-skilled wage rate set by the monopoly labor union depends positively on the low-skilled wage tax rate and the payroll tax rate and negatively on the tax exemption, whereas the high-skilled wage is independent of the high-skilled wage tax parameters.

A higher level and productivity of outsourced production will decrease the wage for the low-skilled labor and increase the wage for the high-skilled labor, thereby inducing higher wage dispersion. A higher low-skilled wage tax will increase the wage for the low-skilled labor and a higher low-skilled wage tax exemption will decrease the wage for the low-skilled labor and increase the wage for the high-skilled labor. A higher payroll tax for the firms will decrease the wage for the low-skilled labor and also under reasonable assumptions decrease the wage for the high-skilled labor. A production mode with a higher amount of outsourced production, ceteris paribus, will reduce equilibrium unemployment of low-skilled workers.

Optimal committed outsourcing will be affected by the policy parameters as follows: a higher domestic low-skilled wage tax and a higher unemployment benefit increase optimal outsourcing, while a higher tax exemption, ceteris paribus, decreases optimal outsourcing. A higher payroll tax for the firms has an ambiguous effect on optimal outsourcing. The effects of tax parameters on low-skilled unemployment are ambiguous, due to conflicting effects. In the absence of outsourcing, a higher wage tax and a lower tax exemption will increase low-skilled unemployment, while a higher payroll tax will have no effect.

There are several new research topics associated with these issues. We have focused on the case where firms decide outsourcing before wage formation. But sometimes firms may be flexible to decide outsourcing activity after wage is set by the 
labor union. Another important issue is to study empirically the implications of labor taxation and labor tax reforms on the level of outsourcing that the firms choose. Finally, we found that the effects of tax parameters were, in the presence of outsourcing, often ambiguous. Numerical analysis could be used to check the role of various parameters.

\section{References:}

Bingley, P. and G. Lanot (2002): The Incidence of Income Tax on Wages and Labour Supply, Journal of Public Economics, 83, 173-194.

Blundell, R.W. and T. MaCurdy (1999): Labour Supply: A Review of Alternative Approaches, in O. Ashenfelter and D. Card (eds) in: Handbook of Labor Economics, vol. 3A, 1559-1604.

Braun, F.D. and J. Scheffel (2007): Does International Outsourcing Depress Union Wages?, SFB 649 Discussion Paper, 2007-033, Humboldt-Universität zu Berlin.

Cahuc, P. and A. Zylberberg (2004): Labor Economics, the MIT Press.

Daveri, F. and G. Tabellini (2000): Unemployment, Growth and Taxation in Industrial Countries, Economic Policy, 30, 49-88.

Davidson, C., S.J. Matusz, and D.R. Nelson (2007): Can Compensation Save Free Trade? Journal of International Economics, 71, 167-186.

Davidson, C., S.J. Matusz, and A. Shevchenko: Globalization and Firm Level Adjustment with Imperfect Labor Markets, forthcoming in Journal of International Economics.

Diehl, M. (1999): The Impact of International Outsourcing on the Skill Structure of Employment: Empirical Evidence from German Manufacturing Industries, Kiel Working Paper No. 946, September.

Egger, H. and P. Egger (2006): International Outsourcing and the Productivity of LowSkilled Labor in the EU, Economic Inquiry, 44, 98-108.

Feenstra, R.C. and G.H. Hanson (1999): The Impact of Outsourcing and HighTechnology Capital on Wages: Estimates for the United States, 1979-1990, Quarterly Journal of Economics, 114, 907-940.

Feenstra, R.C. and G.H. Hanson (2001): Global Production Sharing and Rising Inequality: A Survey of Trade and Wages, NBER Working Paper No. 8372, July.

Freeman, R.B. (2008): Labor Market Institutions Around the World, CEP Discussion

Geishecker, I. and H. Görg (2008): Winners and Losers: A Micro-level Analysis of International Outsourcing and Wages, Canadian Journal of Economics, 41, 243270.

Glass, A.J. and K. Saggi (2001): Innovation and Wage Effects of International Outsourcing, European Economic Review 45, 67-86.

Görg, H. and A. Hanley (2005): Labour Demand Effects of International Outsourcing: Evidence from Plant-Level Data, International Review of Economics and Finance, 14, 365-376.

Hasan. R., D. Mitra and R.V. Ramaswamy (2007): Trade Reforms, Labor Regulations, and Labor-Demand Elasticities: Empirical Evidence from India, the Review of Economics and Statistics, 89(3), 466-481. 
Hijzen, A. (2007): International Outsourcing, Technological Change, and Wage Inequality, Review of International Economics, 15, 188-205.

Hijzen, A., Görg, H. and R.C. Hine (2005): International Outsourcing and the Skill Structure of Labour Demand in the United Kingdom, the Economic Journal, 115, 860-878.

Immervoll, H., H.J. Kleven, C.T. Kreiner and E. Saez (2007): Welfare Reform in European Countries: A Microsimulation Analysis, the Economic Journal, 117, 144.

Koskela, E. and R. Stenbacka (2007): Equilibrium Unemployment with Outsourcing and Wage Solidarity under Labour Market Imperfections, CESifo Working Paper 1988, revised in August 2007.

Koskela, E. and L. von Thadden (2008): Optimal Factor Taxation under Wage Bargaining: A Dynamic Perspective, German Economic Review, 9(2), 135-159.

Lambert, P.J. (2001): The Distribution and Redistribution of Income, $3^{\text {rd }}$ edition, Manchester University Press.

Lingens, J. and K. Waelde (2006): Pareto-Improving Unemployment Policies, CESifo Working Paper No. 1807, September.

Munch, J.R. and J.R. Skaksen (2005): Specialization, Outsourcing and Wages, IZA Discussion Paper No. 1907, December, University of Bonn.

Musgrave, R.A. and T. Thin (1948): Income Tax Progression, 1929-1948, Journal of Political Economy, 56, 498-514.

Nickell, S. and R. Layard (1999): Labor Market Institutions and Economic Performance, in Ashenfelter, O. and D. Card (eds): Handbook of Labor Economics, Volume 3C, 3039-3084.

Pissarides, C.A. (1998): The Impact of Employment Tax Cuts on Unemployment and Wages; the Role of Unemployment Benefits and Tax Structure, European Economic Review, 42, 155-183.

Riley, R. and G. Young (2007): Skill Heterogeneity and Equilibrium Unemployment, Oxford Economic Papers, 59, 702-725.

Senses, M.Z. (2006): The Effects of Outsourcing on the Elasticity of Labor Demand, CES Discussion Paper, Washington D.C., March.

Sinn, H.-W. (2007): The Welfare State and the Forces of Globalization, CESifo Working Paper No. 1925.

Skaksen, J.R. (2004): International Outsourcing When Labour Markets Are Unionized, Canadian Journal of Economics, 37(1), 78-94.

Slaughter, M.J. (2001): International Trade and Labor-Demand Elasticities, Journal of International Economics, 54, 27-56.

Stefanova, B.M. (2006): The Political Economy of Outsourcing in the European Union and the East-European Enlargement, Business and Politics 8, issue 2.

Wood, A. (1998): Globalization and the Rise in Labour Market Inequality, the Economic Journal, 108, 1463-1482.

\section{Appendix A: Optimal Low-Skilled Labor Demand}

Substituting the RHS of (4) for $H$ into (3b) gives 


$$
\begin{aligned}
& \rho\left\{\left(\frac{w_{L}}{w_{H}}\right)^{a}\left(\frac{a}{1-a}\right)^{a}(L+\gamma M)^{a}(L+\gamma M)^{1-a}\right\}^{\rho-1}(1-a)\left(\frac{w_{L}}{w_{H}}\right)^{a}\left(\frac{a}{1-a}\right)^{a}(L+\gamma M)^{a}(L+\gamma M)^{-a} \\
& =\widetilde{w}_{L}
\end{aligned}
$$

so that $\rho\left\{\left(\frac{w_{L}}{w_{H}}\right)^{a}\left(\frac{a}{1-a}\right)^{a}(L+\gamma M)\right\}^{\rho-1}(1-a)\left(\frac{w_{L}}{w_{H}}\right)^{a}\left(\frac{a}{1-a}\right)^{a}=\widetilde{w}_{L}$

which is equivalent to

$$
(L+\gamma M)^{\rho-1}\left(\frac{W_{L}}{w_{H}}\right)^{a \rho}(1-a)\left(\frac{a}{1-a}\right)^{a \rho}=\rho^{-1} \tilde{w}_{L} .
$$

(A3) in its turn gives (5). QED.

\section{Appendix B: Optimal Wage Setting under Progressive Wage Taxation and Proportional Payroll Taxation}

The first-order condition associated with $\underbrace{\max }_{\left(w_{L}\right)} V=\left(\left(1-t_{L}\right) w_{L}+t_{L} e-b_{L}\right) L$ s.t.

$\pi_{L}=0$ and $H^{*}=H^{s}$ can be written as follows

$$
\begin{aligned}
& V_{w_{L}}=\left(1-t_{L}\right) w_{L}\left(1-\left(\hat{\varepsilon}_{L}^{L}+\hat{\varepsilon}_{H}^{L} \frac{d w_{H}}{d w_{L}} \frac{w_{L}}{w_{H}}\right)\right)+\left(b_{L}-t_{L} e\right)\left(\hat{\varepsilon}_{L}^{L}+\hat{\varepsilon}_{H}^{L} \frac{d w_{H}}{d w_{L}} \frac{w_{L}}{w_{H}}\right) \\
& =\left(1-t_{L}\right) w_{L}\left(1-\left(\varepsilon_{L}^{L}+\varepsilon_{H}^{L} \frac{d w_{H}}{d w_{L}} \frac{w_{L}}{w_{H}}\right)\left(1+\gamma \frac{M}{L^{*}}\right)\right)+\left(b_{L}-t_{L} e\right)\left(\varepsilon_{L}^{L}+\varepsilon_{H}^{L} \frac{d w_{H}}{d w_{L}} \frac{w_{L}}{w_{H}}\right)\left(1+\gamma \frac{M}{L^{*}}\right)=0
\end{aligned}
$$

where the own wage elasticity of labor demand is $\hat{\varepsilon}_{L}^{L}=\varepsilon_{L}^{L}\left(1+\gamma \frac{M}{L^{*}}\right)$ and the cross wage elasticity is $\hat{\varepsilon}_{H}^{L}=\varepsilon_{H}^{L}\left(1+\gamma \frac{M}{L^{*}}\right)$ and the labor demand under proportional payroll taxation is $L^{*}=m w_{L}^{-\varepsilon_{L}^{L}} w_{H}^{-\varepsilon_{H}^{L}}(1+s)^{-\varepsilon}-\gamma M=L(\underbrace{w_{L}}_{-}, \underbrace{w_{H}}_{-}, \underbrace{s,}_{-}, \underbrace{\gamma}_{-})$. In the case of the Cobb-Douglas utility function we have

$w_{H}=\left[\frac{\mu(1-a)}{m a}\right]^{-\frac{1}{\varepsilon_{H}^{H}}} w_{L}^{-\frac{\varepsilon_{L}^{H}}{\varepsilon_{H}^{H}}}(1+s)^{-\frac{\varepsilon}{\varepsilon_{H}^{H}}}$

so that 
$\frac{d w_{H}}{d w_{L}}=-\frac{\varepsilon_{L}^{H}}{\varepsilon_{H}^{H}}\left[\frac{\mu(1-a)}{m a}\right]^{-\frac{1}{\varepsilon_{H}^{H}}} w_{L}^{-\frac{\varepsilon_{L}^{H}}{\varepsilon_{H}^{H}}-1}(1+s)^{-\frac{\varepsilon}{\varepsilon_{H}^{H}}}=-\frac{\varepsilon_{L}^{H}}{\varepsilon_{H}^{H}} \frac{w_{H}}{w_{L}}<0$

Using (B2) and (B3) gives $\frac{d w_{H}}{d w_{L}} \frac{w_{L}}{w_{H}}=-\frac{\varepsilon_{L}^{H}}{\varepsilon_{H}^{H}}=-\frac{\rho(1-a)}{1-\rho(1-a)}<0$, which implies the equation (19) because

$\varepsilon_{L}^{L}-\varepsilon_{H}^{L} \frac{\varepsilon_{L}^{H}}{\varepsilon_{H}^{H}}=\frac{\varepsilon_{L}^{L} \varepsilon_{H}^{H}-\varepsilon_{H}^{L} \varepsilon_{L}^{H}}{\varepsilon_{H}^{H}}=\frac{(1-\rho a)(1-\rho(1-a))-\rho a \rho(1-a)}{(1-\rho(1-a))(1-\rho)}=\frac{1}{1-\rho(1-a)}=\beta>1 \mathrm{QED}$

Differentiating (19) in terms of low-skilled wage and wage tax rate gives

$\left(1-\frac{\left[\left(\bar{\varepsilon}_{L}^{L}-1\right) \frac{\partial \bar{\varepsilon}_{L}^{L}}{\partial w_{L}}-\bar{\varepsilon}_{L}^{L} \frac{\partial \bar{\varepsilon}_{L}^{L}}{\partial w_{L}}\right]}{\left(\bar{\varepsilon}_{L}^{L}-1\right)^{2}} \hat{b}_{L}\right) d w_{L}^{*}=\frac{\bar{\varepsilon}_{L}^{L}}{\left(\bar{\varepsilon}_{L}^{L}-1\right)} \frac{b_{L}-e}{\left(1-t_{L}\right)^{2}} d t_{L}$

and using $\hat{b}_{L}=\frac{w_{L}\left(\bar{\varepsilon}_{L}^{L}-1\right)}{\bar{\varepsilon}_{L}^{L}}$ (B4) can be expressed as

$\left(1+\frac{\frac{\partial \bar{\varepsilon}_{L}^{L}}{\partial w_{L}} \frac{w_{L}}{\bar{\varepsilon}_{L}^{L}}}{\left(\bar{\varepsilon}_{L}^{L}-1\right)}\right) d w_{L}^{*}=\frac{\bar{\varepsilon}_{L}^{L}}{\left(\bar{\varepsilon}_{L}^{L}-1\right)} \frac{b_{L}-e}{\left(1-t_{L}\right)^{2}} d t_{L}$

which gives (24a). Equations (24b) and (24c) can be derived in the similar way. QED.

\section{Appendix C: Optimal Committed Outsourcing Before Wage Formation and Domestic Labor Demand}

$$
\begin{aligned}
& \text { By using equations (21) and } \quad \text { (31b) } \quad \text { we } \\
& -\frac{d w_{L}^{*}}{d M}(1+s) L^{*}=\frac{w_{L}^{*} \gamma(1+s) L^{*}}{(\beta-1) L^{*}+(1+\beta) \varepsilon_{L}^{L} \gamma M}>0 \\
& -\frac{\partial w_{H}^{*}}{\partial w_{L}^{*}} \frac{d w_{L}^{*}}{d M}(1+s) H^{*}=-\frac{\varepsilon_{L}^{H}}{\varepsilon_{H}^{H}} \frac{w_{H}^{*} \gamma(1+s) H^{*}}{(\beta-1) L^{*}+(1+\beta) \varepsilon_{L}^{L} \gamma M}<0 .
\end{aligned}
$$

Incorporating (31a), (C1) and (C2) into the first-order condition (30) it can be expressed as 


$$
\begin{aligned}
\pi_{M}= & \left.\gamma(1+s) w_{L}^{*}+\frac{\gamma(1+s) w_{L}^{*} L^{*}}{\left[(\beta-1) L^{*}+(1+\beta) \varepsilon_{L}^{L} \gamma M\right.}\right]-\frac{\varepsilon_{L}^{H}}{\varepsilon_{H}^{H}}\left[\frac{\gamma(1+s) w_{H}^{*} H^{*}}{\left[(\beta-1) L^{*}+(1+\beta) \varepsilon_{L}^{L} \gamma M\right.}\right]^{-c M} \\
= & \gamma(1+s) w_{L}^{*}\left(\frac{\beta L^{*}+(1+\beta) \varepsilon_{L}^{L} \gamma M}{(\beta-1) L^{*}+(1+\beta) \varepsilon_{L}^{L} \gamma M}\right)- \\
& \gamma(1+s) w_{H}^{*} \frac{\varepsilon_{L}^{H}}{\varepsilon_{H}^{H}}\left(\frac{H^{*}}{(\beta-1) L^{*}+(1+\beta) \varepsilon_{L}^{L} \gamma M}\right)-c M \\
= & \left(\frac{\gamma(1+s)}{(\beta-1) L^{*}+(1+\beta) \gamma \varepsilon_{L}^{L} M}\right)\left(w_{L}^{*}\left(\beta L^{*}+(1+\beta) \varepsilon_{L}^{L} \gamma M\right)-w_{H}^{*} \frac{\varepsilon_{L}^{H}}{\varepsilon_{H}^{H}} H^{*}\right)-c M=0
\end{aligned}
$$

Using equation (4) we have $-w_{H}^{*} \frac{\varepsilon_{L}^{H}}{\varepsilon_{H}^{H}} H^{*}=-w_{L}^{*} \frac{\varepsilon_{L}^{H}}{\varepsilon_{H}^{H}} \frac{a}{1-a}\left(L^{*}+\gamma M\right)$ so that

$$
w_{L}^{*}\left(\beta L^{*}+(1+\beta) \varepsilon_{L}^{L} \gamma M\right)-w_{H}^{*} \frac{\varepsilon_{L}^{H}}{\varepsilon_{H}^{H}} H^{*}=w_{L}^{*}\left[L^{*}\left(\beta-\frac{\varepsilon_{L}^{H} a}{\varepsilon_{H}^{H}(1-a)}\right)+\gamma M\left((1+\beta) \varepsilon_{L}^{L}-\frac{\varepsilon_{L}^{H} a}{\varepsilon_{H}^{H}(1-a)}\right)\right]
$$

where $\quad \beta-\frac{\varepsilon_{L}^{H} a}{\varepsilon_{H}^{H}(1-a)}=\frac{1-\rho}{1-\rho(1-a)}=\frac{\varepsilon_{L}^{L}}{\varepsilon_{H}^{H}}>0$

and $(1+\beta) \varepsilon_{L}^{L}-\frac{\varepsilon_{L}^{H} a}{\varepsilon_{H}^{H}(1-a)}=\frac{1}{\varepsilon_{H}^{H}}\left[(1+\beta) \varepsilon_{L}^{L} \varepsilon_{H}^{H}-\varepsilon_{L}^{H} \frac{a}{1-a}\right]=\frac{1}{\varepsilon_{H}^{H}}\left[(1+\beta) \varepsilon_{L}^{L} \varepsilon_{H}^{H}-\varepsilon_{H}^{L}\right]>0$.

Using (C5a) and (C5b) makes it possible to rewrite (C3) as equation (32).

Using $\quad c=\frac{\gamma \varepsilon_{L}^{L}(1+s) w_{L}^{*}}{\varepsilon_{H}^{H} M}\left(\frac{L^{*}+g \gamma M}{X}\right)$ from (32) the second-order condition $\pi_{M M}=-\frac{\gamma^{2} \varepsilon_{L}^{L}(1+s) w_{L}^{*}}{\varepsilon_{H}^{H} X^{2}}\left[L^{*}\left((1+\beta)-\frac{\varepsilon_{L}^{H} \varepsilon_{H}^{L}}{\varepsilon_{L}^{L} \varepsilon_{H}^{H}}\right)\right)+\gamma M\left(g(2-\beta)+(1+\beta) \varepsilon_{L}^{L}\right]-c<0 \quad$ can be

written as

$$
\begin{gathered}
\left.\pi_{M M}=-\frac{\gamma^{2} \varepsilon_{L}^{L}(1+s) w_{L}^{*}}{\varepsilon_{H}^{H} X^{2}}\left[L^{*}\left((1+\beta)-\frac{\varepsilon_{L}^{H}}{\varepsilon_{H}^{H}} \frac{\varepsilon_{H}^{L}}{\varepsilon_{L}^{L}}\right)\right)+\gamma M\left(g(2-\beta)+(1+\beta) \varepsilon_{L}^{L}\right)\right]- \\
\frac{\gamma \varepsilon_{L}^{L}(1+s) w_{L}^{*}}{\varepsilon_{H}^{H} M X^{2}}\left[\left(L^{*}+g \gamma M\right) X\right]=-\frac{\gamma^{2} \varepsilon_{L}^{L}(1+s) w_{L}^{*}}{\varepsilon_{H}^{H} M X^{2}} Z<0,
\end{gathered}
$$

where $Z=L^{*}\left(1+\beta-\frac{\varepsilon_{L}^{H}}{\varepsilon_{H}^{H}} \frac{\varepsilon_{H}^{L}}{\varepsilon_{L}^{L}}\right)+\gamma M\left(g(2-\beta)+(1+\beta) \varepsilon_{L}^{L}\right)+\frac{\left(L^{*}+g \gamma M\right) X}{\gamma M}>0$. 
Concerning equation (35) one term in its numerator can be expressed as follows

$$
\begin{aligned}
& \mathrm{T}=X\left(L^{*}+g \gamma M\right)-\left(X-\left(L^{*}+g \gamma M\right)(\beta-1)\right) \varepsilon_{L}^{L}\left(L^{*}+\gamma M\right)= \\
& X\left(L^{*}+g \gamma M\right)-\gamma M\left[1+\beta+\frac{\varepsilon_{L}^{H} \varepsilon_{H}^{L}}{\varepsilon_{H}^{H}}\right] \varepsilon_{L}^{L}\left(L^{*}+\gamma M\right)
\end{aligned}
$$

By using $X=(\beta-1) L^{*}+(1+\beta) \varepsilon_{L}^{L} \gamma M$ this can be written as

$$
T=(\beta-1) L^{* 2}+\left[(\beta-1) g-\frac{\varepsilon_{H}^{L} \varepsilon_{L}^{H}}{\varepsilon_{H}^{H}}\right] \gamma M L^{*}+\left[(1+\beta)\left(\varepsilon_{L}^{L} g-1\right)-\frac{\varepsilon_{H}^{L} \varepsilon_{L}^{H}}{\varepsilon_{H}^{H}}\right](\gamma M)^{2}>0
$$

so that $\pi_{M t_{L}}>0$ as $b_{L}-e>0$.

Concerning the payroll tax by using equation (26) we can rewrite one term in (39) as follows

$$
\frac{\gamma \varepsilon_{L}^{L}}{\varepsilon_{H}^{H}}\left(w_{L}^{*}+(1+s) \frac{d w_{L}^{*}}{d s}\right)=\frac{\gamma \varepsilon_{L}^{L} w_{L}^{*}}{\varepsilon_{H}^{H}} \frac{[X-\varepsilon \gamma M]}{X}>0 .
$$

Concerning (39) by using $L_{w_{L}^{*}}^{*}=-\frac{\varepsilon_{L}^{L}\left(L^{*}+\gamma M\right)}{w_{L}^{*}}, L_{s}^{*}=-\frac{\varepsilon\left(L^{*}+\gamma M\right)}{1+s}$ and (26) gives

$$
\begin{aligned}
& L_{w_{L}^{*}}^{*} \frac{\partial w_{L}^{*}}{\partial s}+L_{s}^{*}=-\frac{\varepsilon\left(L^{*}+\gamma M\right)}{1+s}\left(\frac{X-\varepsilon_{L}^{L} \gamma M}{X}\right)=-\frac{\varepsilon\left(L^{*}+\gamma M\right)\left[(\beta-1) L^{*}+\beta \varepsilon_{L}^{L} \gamma M\right]}{(1+s) X}= \\
& -\frac{\varepsilon\left(L^{*}+\gamma M\right)\left[X-\varepsilon_{L}^{L} \gamma M\right]}{(1+s) X}<0 .
\end{aligned}
$$

which gives (39'). Concerning (47) using (C7) gives $M\left(L_{w_{L}^{*}}^{*} \frac{\partial w_{L}^{*}}{\partial s}+L_{s}^{*}\right)<0$ and

$$
M L_{w_{L}^{*}}^{*} \frac{\partial w_{L}^{*}}{\partial M} \frac{\partial M}{\partial s}-\left(L^{*}+\gamma M\right) \frac{\partial M}{\partial s}=\frac{\partial M}{\partial s}\left(L^{*}+\gamma M\right)\left(\frac{\varepsilon_{L}^{L} \gamma M}{X}-1\right)=?
$$

This gives (47). QED.

\section{Appendix D: Tax Progression and Low-Skilled Labor Demand}

Substituting the RHS of (50) for $d e / d t_{L}$ into $d w_{L}^{*}=(1-B)\left[\frac{\partial w_{L}^{*}}{\partial t_{L}} d t_{L}+\frac{\partial w_{L}^{*}}{\partial e} d e\right]$ implies 
$\left.\frac{d w_{L}^{*}}{d t_{L}}\right|_{d R=0}=\frac{\left(\frac{\partial w_{L}^{*}}{\partial t_{L}}(1-B) t_{L}\left(1-\frac{e}{w_{L}^{*}} \frac{\partial w_{L}^{*}}{\partial e}(1-B)\right)+\frac{\partial w_{L}^{*}}{\partial e}\left(w_{L}^{*}-e\right)(1-B)+\frac{\partial w_{L}^{*}}{\partial e}(1-B) \frac{t_{L} e}{w_{L}^{*}} \frac{\partial w_{L}^{*}}{\partial t_{L}}(1-B)\right)}{t\left[1-\frac{e}{w_{L}^{*}} \frac{\partial w_{L}^{*}}{\partial e}(1-B)\right]}$

which gives (51), where the denominator is positive. Concerning $\frac{\partial w_{L}^{*}}{\partial t_{L}}+\frac{\left(w_{L}^{*}-e\right)}{t_{L}} \frac{\partial w_{L}^{*}}{\partial e}$ in (51) we obtain that it is negative, i.e.

$$
\frac{\partial w_{L}^{*}}{\partial t_{L}}+\frac{\left(w_{L}^{*}-e\right)}{t_{L}} \frac{\partial w_{L}^{*}}{\partial e}=\frac{U}{\left(1-t_{L}\right)^{2}}\left(b_{L}-w_{L}^{*}\right)<0
$$

where $\quad U=\frac{\beta\left(L^{*}+\gamma M\right)}{(\beta-1) L^{*}+(1+\beta) \varepsilon_{L}^{L} \gamma M}>0$. The total labor demand effect $d L^{*}=L_{w_{L}^{*}}^{*}(1-B)\left[\frac{\partial w_{L}^{*}}{\partial t_{L}} d t_{L}+\frac{\partial w_{L}^{*}}{\partial e} d e\right]-\gamma\left[M_{t_{L}} d t_{L}+M_{e} d e\right]$ can be expressed as

$\left.\frac{d L^{*}}{d t_{L}}\right|_{d R=0}=L_{w_{L}^{*}}^{*}(1-B)\left[\frac{\partial w_{L}^{*}}{\partial t_{L}}+\left.\frac{\partial w_{L}^{*}}{\partial e} \frac{d e}{d t_{L}}\right|_{d R=0}\right]-\gamma\left[M_{t_{L}}+\left.M_{e} \frac{d e}{d t_{L}}\right|_{d R=0}\right]$

where $\frac{\partial w_{L}^{*}}{\partial t_{L}}+\left.\frac{\partial w_{L}^{*}}{\partial e} \frac{d e}{d t_{L}}\right|_{d R=0}=\left.\frac{d w_{L}^{*}}{d t_{L}}\right|_{d R=0}<0$ (equation (51)) and by using $M_{e}=\frac{M_{t_{L}}}{\frac{\partial w_{L}^{*}}{\partial t_{L}}} \frac{\partial w_{L}^{*}}{\partial e}$

from (37) and (38) gives

$\left.\frac{d M}{d t_{L}}\right|_{d R=0}=\left[M_{t_{L}}+\left.M_{e} \frac{d e}{d t_{L}}\right|_{d R=0}\right]=M_{t_{L}}+M_{e} \frac{\left[\frac{w_{L}^{*}-e}{t_{L}}+\frac{e}{w_{L}^{*}} \frac{\partial w_{L}^{*}}{\partial t_{L}}(1-B)\right]}{\left[1-\frac{e}{w_{L}^{*}} \frac{\partial w_{L}^{*}}{\partial e}(1-B)\right]}=$

$\frac{M_{t_{L}}}{\frac{\partial w_{L}^{*}}{\partial t_{L}}} \frac{\left[\frac{\partial w_{L}^{*}}{\partial t_{L}}+\frac{\left(w_{L}^{*}-e\right)}{t_{L}} \frac{\partial w_{L}^{*}}{\partial e}\right]}{\left[1-\frac{e}{w_{L}^{*}} \frac{\partial w_{L}^{*}}{\partial e}(1-B)\right]}<0$

which gives (52). QED. 